\title{
Further improvement and evaluation of nudging in the E3SM Atmosphere Model version 1 (EAMv1)
}

\author{
Shixuan Zhang ${ }^{1}$, Kai Zhang ${ }^{1}$, Hui Wan ${ }^{1}$, and Jian Sun ${ }^{1,2}$ \\ ${ }^{1}$ Pacific Northwest National Laboratory, Richland, Washington, USA \\ ${ }^{2}$ National Center for Atmospheric Research, Boulder, CO, USA
}

Correspondence: Shixuan Zhang (Shixuan.Zhang@pnnl.gov) and Kai Zhang (Kai.Zhang@pnnl.gov)

\begin{abstract}
A previous study on the use of nudging in EAMv1 had an unresolved issue, namely a simulation nudged to EAMv1's own meteorology showed non-negligible deviations from the free-running baseline simulation over some of the subtropical marine stratocumulus and trade cumulus regions. Here, we demonstrate the deviations can be substantially reduced by two changes in the nudging implementation: first, revising the sequence of calculations in a nudged EAM simulation to improve consistency with the free-running baseline; second, increasing the frequency of constraining data from 6-hourly to 3-hourly to better capture strong sub-diurnal variations.

The resulting improvements in climate representativeness motivate an investigation on the potential benefits of using newer reanalysis products with higher data frequency in nudged simulations that aim at capturing observed weather events. Simulations nudged towards 6-hourly ERA-Interim reanalysis or 6-hourly, 3-hourly, and hourly ERA5 reanalysis are evaluated against EAMv1's own climatology, global-scale satellite retrievals of outgoing longwave radiation and precipitation, as well as in-situ measurements of air temperature, humidity, and winds from the Atmospheric Radiation Measurement (ARM) user facility. Our overall recommendation is to use the revised sequence of calculation and 3-hourly data from ERA5 for the nudged simulations.

The anthropogenic aerosol effects in various EAMv1 simulations are evaluated. For estimating the global mean effect, the source of constraining data has a relatively small impact. Consistent with conclusions from previous studies, in order to obtain estimates of global mean aerosol effects that are consistent with results from the free-running baseline, nudging the horizontal winds but not air temperature is recommended.
\end{abstract}

\section{Introduction}

Nudging (or Newtonian relaxation) is widely used to diagnose model sensitivities in climate models caused by model formulation or tuning (Lohmann and Hoose, 2009; Zhang et al., 2012; Separovic et al., 2012; Lin et al., 2016), computational methods (Wan et al., 2014) or external forcing (Kooperman et al., 2012; Zhang et al., 2014). These studies have shown that nudging can help reduce noise in sensitivity experiments resulting from natural variability, by constraining the large-scale meteorological conditions (e.g. horizontal winds) toward weather reanalysis or a baseline simulation, and hence allow for the detection of signals without requiring long simulations or large ensembles (e.g., Kooperman et al., 2012). However, nudging should be used with care based on the purpose of the study and thoroughly evaluated. Many studies have shown that the forcing terms 
https://doi.org/10.5194/gmd-2022-10

Preprint. Discussion started: 3 February 2022

(C) Author(s) 2022. CC BY 4.0 License.

\section{(c) (i)}

introduced by nudging can be sufficiently strong to break the internal balance between dynamics and physics (e.g. Jeuken et al., 1996) or to cause significant changes in the model's climate (e.g. Zhang et al., 2014), making the results less useful for interpreting the behavior of the original model.

Sun et al. (2019) evaluated two types of nudged simulations conducted with the atmosphere component of the Energy Exascale Earth System Model version 1 (EAMv1, Rasch et al., 2019; Xie et al., 2018): one type was constrained by reanalyses products, and the second type was constrained by the meteorological fields written out from a free-running baseline simulation conducted with the same model (hereafter referred to as the "baseline nudging" method). They showed that simulations using baseline nudging closely resembled the free-running baseline for the key meteorological variables evaluated therein, as evidenced by the high spatial and temporal correlations between the nudged and free-running simulations. On the other hand, systematic decreases in the annual mean shortwave cloud radiative forcing (SWCF) were observed in subtropical and tropical regions when nudging was used, with local annual averages as large as $8 \mathrm{~W} \mathrm{~m}^{-2}$. The discrepancies are inconvenient as they result in inaccuracies in the anthropogenic aerosol effects estimated using baseline-nudging.

The study presented here starts with an effort to address these discrepancies. The sequence of calculations related to nudging in EAMv1's time integration cycle is reviewed (Sections 2.2 and 3.1) and the time-step-by-time-step temporal evolution of the model state in the subtropics is analyzed (Section 3.2). We demonstrate that the discrepancy issue in Sun et al. (2019) can be substantially alleviated by two revisions of the nudging implementation: first, changing the sequence of calculations in a nudged EAM simulation to improve consistency with the free-running baseline; second, increasing the frequency of constraining data from 6-hourly to 3-hourly to better capture strong sub-diurnal variations. The resulting improvements in climate representativeness are presented in Section 3.

Motivated by the improvements, additional simulations and analyses are presented in Section 4 to explore the potential benefits of using newer reanalysis products with higher data frequency in nudged simulations that aim at capturing observed weather events. In many previous studies (e.g., Telford et al., 2008; Zhang et al., 2014), the reanalysis products used for generating the nudging data, e.g. ERA-Interim (Dee et al., 2011) from the European Centre for Medium-Range Weather Forecasts (ECMWF) or the National Centers for Environmental Prediction and National Center for Atmospheric Research (NCEP/NCAR) Reanalysis (Kanamitsu et al., 2002), were only available 4 times per day. In recent years, reanalysis data with 50 high temporal frequency are emerging. For example, MERRA-2 (Gelaro et al., 2017) from the NASA GMAO is available every 3 hours, while ERA5 from ECMWF (Hersbach et al., 2020) provides hourly data. On the one hand, using high-frequency reanalysis data for nudging may provide a better constraint for the nudged simulation. On the other hand, it will increase the computational cost, since the nudging data need to be processed in advance and read in during a simulation. Handling higher frequency nudging data requires more storage and more I/O access. Therefore, it is useful to evaluate the benefit of using high-frequency reanalysis nudging data. Furthermore, since ERA5 is a new reanalysis product that has not been widely used for nudged simulations, it is useful to compare simulations nudged towards ERA5 and ERA-interim, evaluate hindcast skills of these simulations, and provide a recommendation. For this purpose, we present in Section 4 simulations constrained using 6-hourly ERA-Interim reanalysis or 6-hourly, 3-hourly, or hourly ERA5 reanalysis. Hindcast skills of the nudged EAM simulations are evaluated against global-scale satellite retrievals of outgoing longwave radiation and precipitation, as well 

(ARM) user facility. Since one of our primary interests in using nudged simulations is to efficiently estimate the climate impact of anthropogenic aerosols, we also present some analysis on the sensitivity of the estimates to nudging implementation in Section 5. Our findings and recommendations are summarized in Section 6.

\section{Model and simulations}

\subsection{A brief overview of EAMv1}

E3SM is a global Earth system model developed by the U.S. Department of Energy (Golaz et al., 2019). The present study focuses on nudging applications in the E3SM Atmosphere Model version 1 (EAMv1; Rasch et al., 2019; Xie et al., 2018). EAMv1 uses the hydrostatic spectral element (SE) dynamical core on a cubed-sphere mesh (Dennis et al., 2012; Taylor et al., 2010) to solve the equations for large-scale dynamics and tracer transport. The key subgrid-scale physical processes considered in EAMv1 include deep convection (hereafter Deep Cu; Zhang and McFarlane, 1995), turbulence and shallow convection (Golaz et al., 2002; Larson et al., 2002), cloud microphysics (Morrison and Gettelman, 2008; Gettelman and Morrison, 2015; Wang et al., 2014), aerosol life cycle (Liu et al., 2016; Wang et al., 2020), and radiation (Iacono et al., 2008; Mlawer et al., 1997). EAMv1 is interactively coupled with a land model (Oleson et al., 2013).

Figure 1a shows the sequence of dynamics and physics calculations (i.e., the time integration loop) in EAMv1. More detailed descriptions of the time stepping and coupling of physics and dynamics can be found in Zhang et al. (2018) and Wan et al. (2021). One important feature relevant to the discussion below is that most of the atmospheric processes are numerically coupled using sequential splitting. This means after a model component (e.g., a parameterization) predicts the rate-of-change (also called tendency) of the model state caused by the atmospheric process it represents, the model state will be updated using the predicted tendency before being handled to the next model component (e.g., another parameterization).

The model used in this study has a horizontal resolution of approximately $1^{\circ}(\sim 110 \mathrm{~km})$. There are 72 layers in the vertical, extending from the Earth's surface to $\sim 0.1 \mathrm{hPa}(\sim 64 \mathrm{~km})$. The vertical grid spacing is uneven, with the layer height ranging from 20-100 m near the surface and up to $600 \mathrm{~m}$ near the model top.

\subsection{Nudging in EAMv1}

The nudging implementation in EAMv1 was described and evaluated in Sun et al. (2019), so we only provide a brief introduction here. Nudging constrains the model solution toward prescribed atmospheric conditions for a certain variable by adding a relaxation term to the prognostic equation:

$$
\left(\frac{\partial X_{m}}{\partial t}\right)_{\mathrm{ndg}}=-\frac{X_{m}-X_{p}}{\tau}
$$

where $X$ in Eq. (1) represents a model state variable like horizontal wind (U, V), temperature (T), or specific humidity (Q). Subscript $m$ refers to the model-predicted value. Subscript $p$ indicates the prescribed field that is taken or derived from either 
90 a global weather reanalysis or a free-running simulation using the same model. $\tau$ denotes the relaxation time scale. All three quantities, $X_{m}, X_{p}$, and $\tau$, can affect the sign and strength of the nudging-induced forcing.

Pink boxes in the left panel of Figure 1 illustrate where the nudging-related calculations occur in the default EAMv1. In a nudged simulation, a forcing term in the form of Eq. (1) is calculated for each nudged prognostic variable, with $X_{m}$ being the value of $X$ after the dynamical core. These forcing terms are used to update the model state variables after the physics parameterization suite (before the next call of the dynamical core). When an EAM simulation is considered to be a baseline simulation, the dynamical and thermodynamical variables (e.g., U, V, T, Q, and the surface pressure PS) that are archived and used subsequently in a nudged simulation as the prescribed atmospheric state - are the values saved before the radiation calculation (cf. pink dashed box in Fig. 1a).

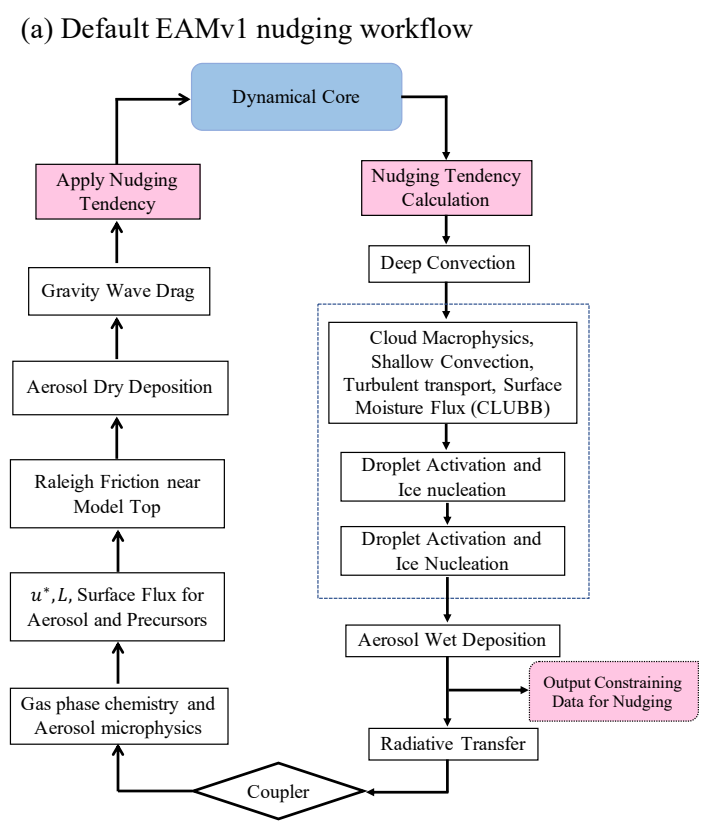

(b) Revised EAMv1 nudging workflow

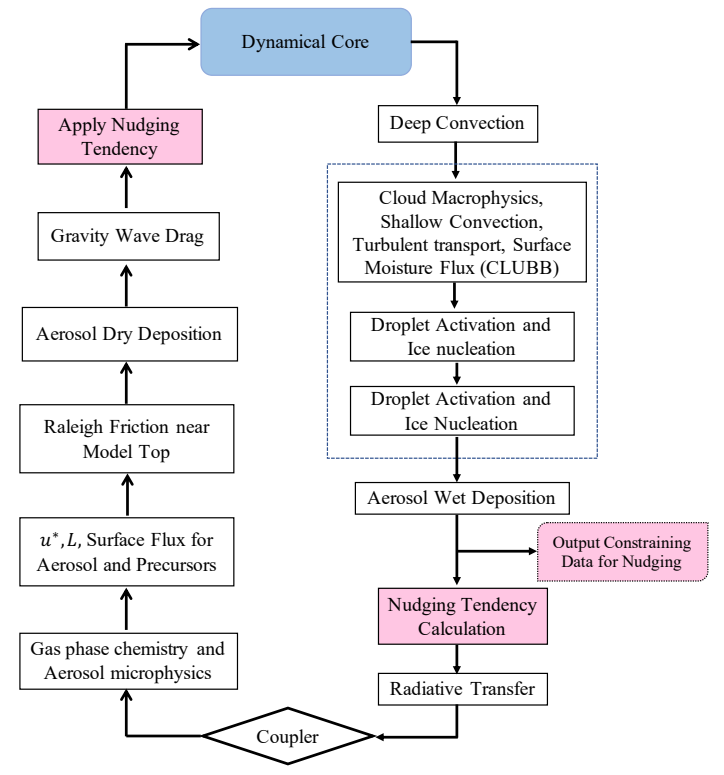

Figure 1. Flowcharts showing the sequence of dynamics and physics calculations within one time step in an EAMv1 simulation. Pink boxes indicate where the nudging-related calculations occur. Panel (a) is adapted from Fig. S1 in Sun et al. (2019) and corresponds to the default EAMv1 code. Panel (b) is the revised sequence of calculation evaluated in this study. The key difference is that in panel (b), the calculation of nudging tendency using Eq. (1) occurs at the same location where the prescribed meteorological state is written out in the baseline simulation, i.e., before the radiation parameterization. Panel (b) is described in detail in Section 3.1.

\subsection{Simulations}

The EAMv1 simulations presented in this paper are summarized in Table 1. All the simulations involved active atmosphere and land but used prescribed sea surface temperature (SST) and sea ice extension, following the protocol from the Atmospheric Model Intercomparison Project (Gates et al., 1999). The SST and sea ice extension used in this study are weekly data from 
https://doi.org/10.5194/gmd-2022-10

Preprint. Discussion started: 3 February 2022

(C) Author(s) 2022. CC BY 4.0 License.

the National Oceanic and Atmospheric Administration (NOAA) Optimum Interpolation (OI) analysis (Reynolds et al., 2002). Other external forcings, including volcanic aerosols, solar variability, concentrations of greenhouse gases, and anthropogenic emissions of aerosols and their precursors, were prescribed following the World Climate Research Programme (WCRP) Coupled Model Intercomparison Project-Phase 6 (CMIP6; Eyring et al., 2016; Hoesly et al., 2018; Feng et al., 2020). Emissions of aerosols and their precursor gases of the year 2010 are used to represent the present-day (PD) condition.

All simulations were performed from 1 October 2009 to 31 December 2010. The first 3 months were discarded as model spin-up, and the remaining 1 year of model output was used for analysis. The choice of simulation year was based on convenience, as hourly ERA5 data of 2010 were readily available to us. Sun et al. (2019) have shown that the annual mean cloud radiative forcing and its shortwave and longwave components derived from 1-year nudged simulations were representative of the corresponding longer-term (e.g., 5-year) statistics (see, e.g., Fig. 19 therein).

The first group of simulations presented in this paper is an ensemble of five 15-month simulations. The first ensemble member is a free-running baseline simulation referred to as CLIM in the remainder of the paper, from which the before-radiation values of U, V, T, Q, and PS were archived at 1-hour, 3-hour, and 6-hour frequencies to constrain subsequent simulations. The other four ensemble members were nudged to 6-hourly temperature output from CLIM but using long relaxation time scales of 10 days, 10.1 days, 10.2 days, 10.3 days, respectively. These relaxation time scales correspond to values of $1 / \tau$ on the order of $10^{-6}$, which resulted in physically insignificant constraints on the simulations. Therefore, the four ensemble members can effectively be considered free-running although with perturbations introduced to the $3 \mathrm{D}$ temperature field that can be used to quantify natural variability in the evolution of the atmospheric state. A similar experimentation strategy has been used by Liu et al. (2018) to generate hindcast ensembles to investigate the radiative forcing of fire-emitted aerosols.

The second group of simulations was constrained by meteorology archived from CLIM with nudging applied at all time steps and all vertical levels, using a $6 \mathrm{~h}$ relaxation time scale. The two simulations DNDG_UV6 and DNDG_UVT6 used the sequence of calculation shown in Fig. 1a while RNDG_UV6 and RNDG_UVT6 used the revised sequence shown in Fig. 1b and explained in Section 3.1. The impact of the revised sequence of calculation is evaluated in Section 3.1. The difference in simulation setup between each pair of experiments labeled "_UV" and "_UVT" is whether only the horizontal winds were nudged (“_UV”) or both winds and temperature were nudged (“_UVT”). The number 6 in the experiment names indicates the use of 6-hourly output from CLIM. Two additional pairs of simulations were conducted, also using the revised sequence, but constrained by 3-hourly or 1-hourly output from CLIM. These two pairs (RNDG_UV3 and RNDG_UVT3, RNDG_UV1 and RNDG_UVT1) are compared with RNDG_UV6 and RNDG_UVT6 in Section 3.2 to evaluate the impact of the frequency of the constraining data .

The third group of simulations was nudged toward two reanalysis products, ERA-Interim (Dee et al., 2011) and ERA5 (Hersbach et al., 2020), to assess whether using a newer product (ERA5) and its higher data frequency, instead of the older ERA-Interim at 6-hour intervals, can provide nudged hindcast simulations that agree better with observational data. The reanalysis products were spatially remapped to the cubed-sphere grid and 72 model layers used by EAMv1, following the method used in the Community Earth System Model Version 2 (CESM2; https://ncar.github.io/CAM/doc/build/html/users_ guide/physics-modifications-via-the-namelist.html\#nudging). Topographical differences between EAMv1 and the reanalysis 
https://doi.org/10.5194/gmd-2022-10

Preprint. Discussion started: 3 February 2022

(c) Author(s) 2022. CC BY 4.0 License.

(c) (i)

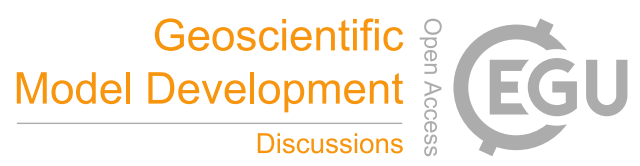

model were taken into account during the vertical interpolation. This group of simulations are compared to global or quasiglobal observational data of surface precipitation rate and the top of atmosphere outgoing longwave radiation from satellite retrievals (Section 4.2) as well as in-situ measurements from the Atmospheric Radiation Measurement (ARM) program (Section 4.3).

For selected model configurations (cf. Table 1), we also performed simulations using the pre-industrial (PI, year 1850) aerosol and precursor gas emissions while keeping the greenhouse gas concentrations, SST, and sea ice extent unchanged from the PD simulations. These PI simulations are used to assess the impact of nudging strategy on the estimates of the direct and indirect radiative effects of the anthropogenic aerosols (Section 5).

Table 1. List of simulations described in Section 2.3. Nudging was applied at each physics time step. A 6-h relaxation time scale was used for group 2 and 3 nudged simulations. For the "CLIMpx" simulations, very long relaxation time scales (about 10 days) were applied to generate ensemble members in addition to CLIM. Simulations using present-day (PD, year 2010) external forcing were carried out with all listed configurations. Pre-industrial (PI, year 1850) emissions of aerosols and precursors were used to carry out additional simulations for a subset of the configurations (see the right-most column).

\begin{tabular}{|c|c|c|c|c|c|c|}
\hline $\begin{array}{l}\text { Group } \\
\text { number }\end{array}$ & $\begin{array}{l}\text { Simulation } \\
\text { short name }\end{array}$ & Flowchart & Nudged variables & $\begin{array}{l}\text { Constraining data } \\
\text { and frequency }\end{array}$ & $\begin{array}{l}\text { Nudging relaxation } \\
\text { time scale }\end{array}$ & $\begin{array}{l}\text { Aerosol and precursor } \\
\text { gas emissions }\end{array}$ \\
\hline 1 & CLIM & Fig. 1a & None & N/A & N/A & PD and PI \\
\hline 1 & CLIMp1 & Fig. 1a & $\mathrm{T}$ & CLIM (6 hr) & 10.1 days & PD and PI \\
\hline 1 & CLIMp2 & Fig. 1a & $\mathrm{T}$ & CLIM (6 hr) & 10.2 days & PD and PI \\
\hline 1 & CLIMp3 & Fig. 1a & $\mathrm{T}$ & CLIM (6 hr) & 10.3 days & PD and PI \\
\hline 1 & CLIMp4 & Fig. 1a & $\mathrm{T}$ & CLIM (6 hr) & 10.4 days & PD and PI \\
\hline 2 & DNDG_UV6 & Fig. 1a & $\mathrm{U}, \mathrm{V}$. & CLIM (6 hr) & $6 \mathrm{hr}$ & PD \\
\hline 2 & DNDG_UVT6 & Fig. 1a & $\mathrm{U}, \mathrm{V}, \mathrm{T}$ & CLIM (6 hr) & $6 \mathrm{hr}$ & PD and PI \\
\hline 2 & RNDG_UV6 & Fig. 1b & $\mathrm{U}, \mathrm{V}$ & CLIM (6 hr) & $6 \mathrm{hr}$ & PD and PI \\
\hline 2 & RNDG_UVT6 & Fig. 1b & $\mathrm{U}, \mathrm{V}, \mathrm{T}$ & CLIM (6 hr) & $6 \mathrm{hr}$ & PD and PI \\
\hline 2 & RNDG_UV3 & Fig. 1b & $\mathrm{U}, \mathrm{V}$ & CLIM (3 hr) & $6 \mathrm{hr}$ & PD \\
\hline 2 & RNDG_UVT3 & Fig. 1b & $\mathrm{U}, \mathrm{V}, \mathrm{T}$ & CLIM (3 hr) & $6 \mathrm{hr}$ & PD and PI \\
\hline 2 & RNDG_UV1 & Fig. 1b & $\mathrm{U}, \mathrm{V}$ & CLIM (1 hr) & $6 \mathrm{hr}$ & PD \\
\hline 2 & RNDG_UVT1 & Fig. 1b & $\mathrm{U}, \mathrm{V}, \mathrm{T}$ & CLIM (1 hr) & $6 \mathrm{hr}$ & PD \\
\hline 3 & DNDG_ERAI_UV6 & Fig. 1a & $\mathrm{U}, \mathrm{V}$ & ERA-Interim ( $6 \mathrm{hr}$ ) & $6 \mathrm{hr}$ & PD \\
\hline 3 & DNDG_ERAI_UVT6 & Fig. 1a & $\mathrm{U}, \mathrm{V}, \mathrm{T}$ & ERA-Interim ( $6 \mathrm{hr}$ ) & $6 \mathrm{hr}$ & PD \\
\hline 3 & RNDG_ERAI_UV6 & Fig. $1 \mathrm{~b}$ & $\mathrm{U}, \mathrm{V}$ & ERA-Interim $(6 \mathrm{hr})$ & $6 \mathrm{hr}$ & PD \\
\hline 3 & RNDG_ERAI_UVT6 & Fig. 1b & $\mathrm{U}, \mathrm{V}, \mathrm{T}$ & ERA-Interim $(6 \mathrm{hr})$ & $6 \mathrm{hr}$ & PD \\
\hline 3 & RNDG_ERA5_UV6 & Fig. $1 \mathrm{~b}$ & $\mathrm{U}, \mathrm{V}$ & ERA5 (6 hr) & $6 \mathrm{hr}$ & $\mathrm{PD}$ and PI \\
\hline 3 & RNDG_ERA5_UVT6 & Fig. 1b & $\mathrm{U}, \mathrm{V}, \mathrm{T}$ & ERA5 (6 hr) & $6 \mathrm{hr}$ & PD and PI \\
\hline 3 & RNDG_ERA5_UVT3 & Fig. $1 \mathrm{~b}$ & $\mathrm{U}, \mathrm{V}, \mathrm{T}$ & ERA5 (3 hr) & $6 \mathrm{hr}$ & PD \\
\hline 3 & RNDG_ERA5_UVT1 & Fig. 1b & $\mathrm{U}, \mathrm{V}, \mathrm{T}$ & ERA5 (1 hr) & $6 \mathrm{hr}$ & PD \\
\hline
\end{tabular}



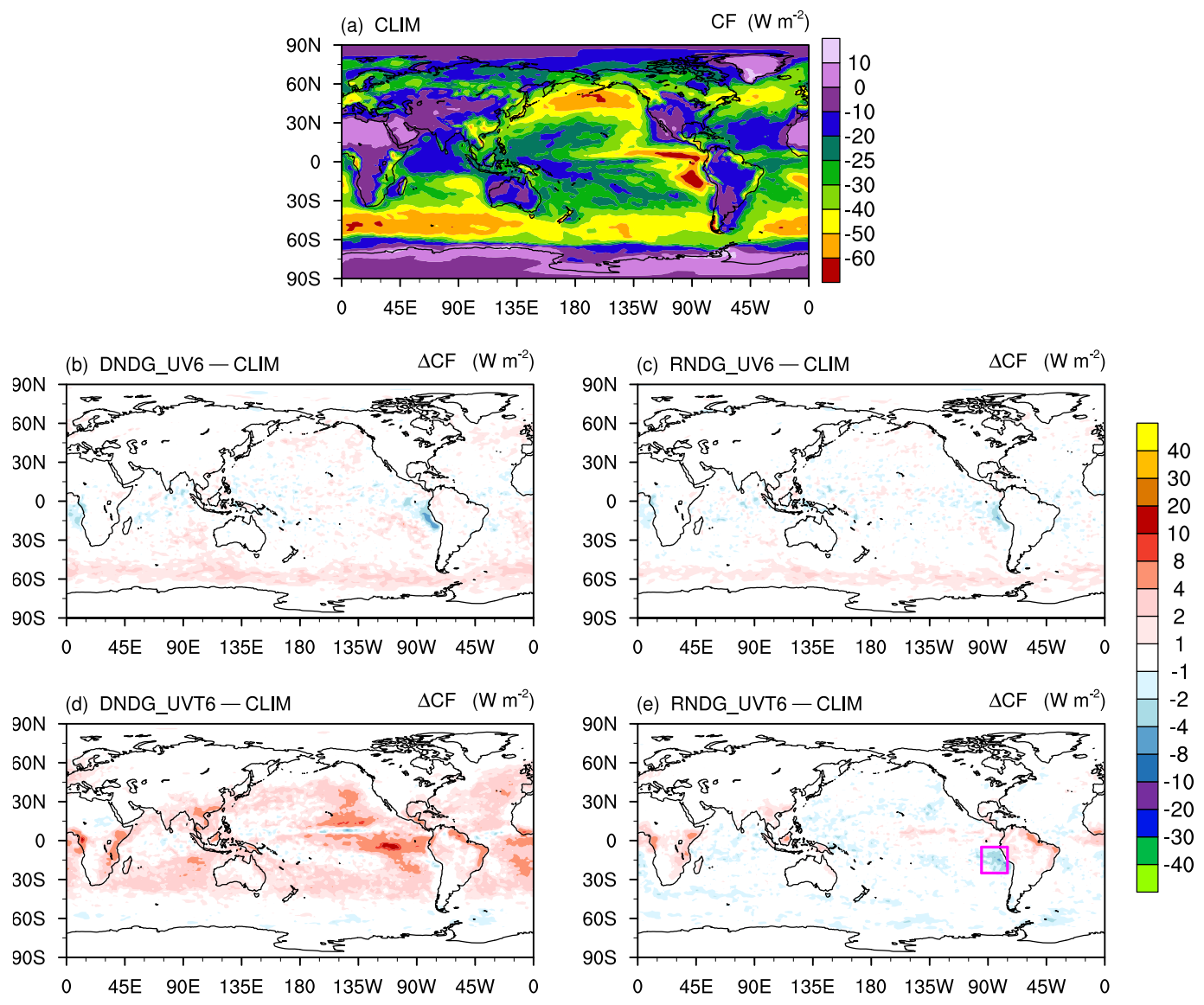

Figure 2. Global annual mean total cloud radiative forcing (CF, unit: $\mathrm{W} \mathrm{m}^{-2}$ ) in the free-running simulation (CLIM, panel a) and the differences between nudged simulations and CLIM (panels b-e). Descriptions of the simulation setups can be found in Section 2.3 and Table 1. The magenta box over the Peruvian stratocumulus region in panel (e) is further analyzed in Fig. 3.

\section{Improving climate representativeness of simulations nudged to CLIM}

Before this work, the EAMv1 simulations nudged to 6-hourly output from CLIM were known to show non-negligible differences from CLIM. For example, Fig. 15b in Sun et al. (2019) showed the weakening of 1-year mean SWCF on the order of 2-8 $\mathrm{W} \mathrm{m}^{-2}$ in large areas of the subtropical marine and coastal regions when horizontal winds and temperature were both nudged. The differences exceeded $8 \mathrm{~W} \mathrm{~m}^{-2}$ in some regions over the southeast Pacific Ocean and South America. Figure 15a in that same paper showed that constraining only the horizontal winds (i.e., no temperature nudging) would remove the discrepancies in most of the subtropical regions, although one would find 4-8 $\mathrm{W} \mathrm{m}^{-2}$ of strengthening of the annual mean SWCF close to the coast of Peru. The corresponding discrepancies seen in the total cloud forcing (CF) and cloud cover are shown in panels (b) and (d) of Fig. 2 and Fig. A1 in this paper. When winds and temperature are both nudged, we see a substantial number of grid cells in the subtropical Pacific and Atlantic oceans where the relative differences on the order of $10 \%$ to $20 \%$ 
are seen in total CF when compared to the annual mean total CF in the baseline simulation CLIM (Fig. A2d). Discrepancies of such magnitudes are counterintuitive since the constraining data were generated from the same model driven by the same external forcing. On the other hand, since nudging introduces forcing terms in the form of Eq. (1) to the model's governing equations, any differences between $X_{m}$ and $X_{p}$ will lead to deviations from a free-running simulation. Below, we show that such deviations can be significantly reduced by revising the sequence of calculations in nudged simulations and thereby achieving better consistency with the free-running baseline (Section 3.1), as well as by increasing the data frequency of the constraining meteorology to better capture higher-frequency variations in time (Section 3.2).

\subsection{Calculation of nudging tendency}

As mentioned in Section 2.2, in EAMv1's nudging implementation before this study, the baseline simulation's atmospheric state was archived before the radiation parameterization while the nudging-induced forcing (i.e., Eq. (1)) was calculated after the dynamical core. Since EAMv1 uses sequential splitting to couple most of the atmospheric processes (cf. Section 2.1), if we use a subscript "DYN" to label the atmospheric state after the dynamical core and a subscript "ARC" to label the atmospheric state being archived, then the the old nudging implementation was, effectively,

$$
\begin{aligned}
\left(\frac{\partial X_{m}}{\partial t}\right)_{\mathrm{ndg}} & =-\frac{X_{\mathrm{m}, \mathrm{DYN}}-X_{\mathrm{p}, \mathrm{ARC}}}{\tau} \\
& =\left(-\frac{X_{\mathrm{m}, \mathrm{ARC}}-X_{\mathrm{p}, \mathrm{ARC}}}{\tau}\right)+\left(\frac{X_{\mathrm{m}, \mathrm{ARC}}-X_{\mathrm{m}, \mathrm{DYN}}}{\tau}\right)
\end{aligned}
$$

In our understanding, the first term on the right-hand side of Eq. (3) is the intended nudging tendency while the second term is inadvertent. Furthermore, the second term can be understood as the total tendency caused by deep convection, turbulence, and stratiform cloud parameterizations scaled by a factor of $\Delta t / \tau$ where $\Delta t$ is the physics time step. Since these moist processes are known to strongly affect the atmospheric state, especially temperature and humidity, it is not surprising that nudged simulations using Eq. (2) deviate from their free-running baseline.

When the calculation of the nudging tendency is moved before the radiation parameterization so that $X_{p}$ from the baseline simulation and $X_{m}$ in the nudged simulation come from the same location of the time integration cycle (see schematic in Fig. 1b), we will have, as intended,

$$
\left(\frac{\partial X_{m}}{\partial t}\right)_{\mathrm{ndg}}=-\frac{X_{\mathrm{m}, \mathrm{ARC}}-X_{\mathrm{p}, \mathrm{ARC}}}{\tau} .
$$

Sensitivity experiments confirm that using Eq. (4) instead of Eq. (2) signficantly reduces discrepancies between the UVTnudged and free-running simulations, as can be seen by comparing Fig. 2e with $2 \mathrm{~d}$. The annual mean total CF differences are reduced to within $1 \mathrm{~W} \mathrm{~m}^{-2}$ for the majority of the grid cells and within $2 \mathrm{~W} \mathrm{~m}^{-2}$ in the subtropics and tropics, with only a small number of grid cells showing differences between $2-5 \mathrm{~W} \mathrm{~m}^{-2}$. The discrepancies between UV-nudged and free-running simulations are also reduced, although not as significantly (Fig. $2 c$ versus $2 b$ ). The remaining discrepancies are investigated in the next subsection. 


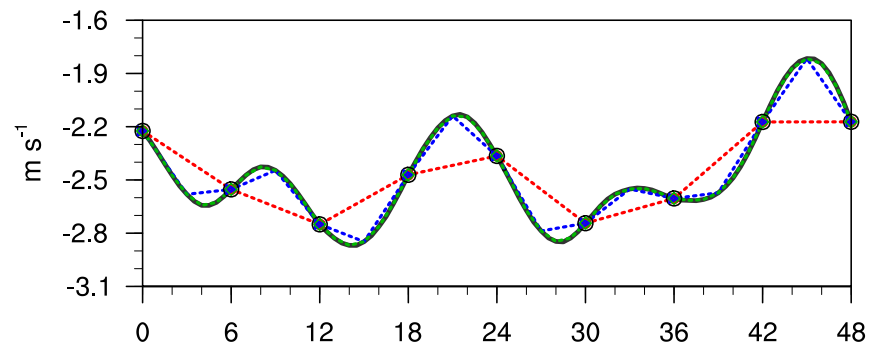

(b) temperature

Peruvian stratocumulus region

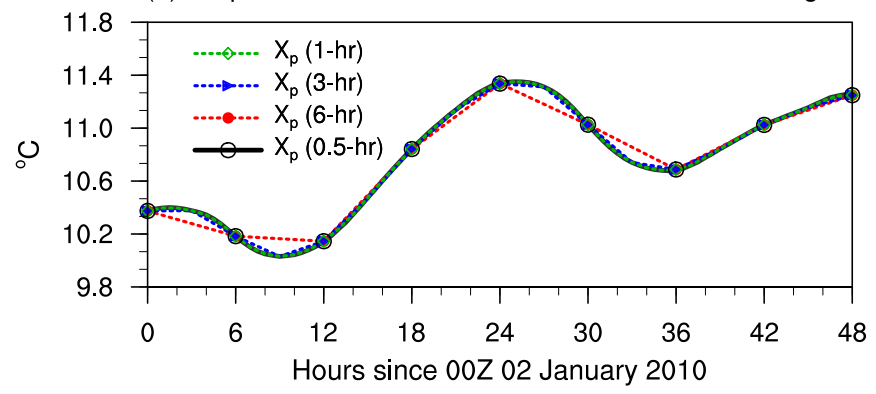

Figure 3. Time evaluation of (a) zonal wind (unit: $\mathrm{m} \mathrm{s}^{-1}$ ) and (b) temperature (unit: ${ }^{\circ} \mathrm{C}$ ) at the model level closest to $700 \mathrm{hPa}$ during a 48 -h period starting from 00Z 02 January 2010. The values shown are horizontal averages of the magenta box in Fig. 4e. The black thick lines are time-step-by-time-step output from CLIM. The red, blue, and green lines are time-step-by-time-step values of $X_{p}$ in Eq. (1) that were obtained by linear temporal interpolation using 6-hr, 3-hr and 1-hr output of CLIM.

\subsection{Frequency of constraining data}

Nudged simulations in the literature (e.g., Kooperman et al., 2012; Subramanian and Zhang, 2014; Ma et al., 2014, 2015; Lin et al., 2016; Fast et al., 2016), including our own work (e.g., Zhang et al., 2014; Sun et al., 2019), often used 6-hourly constraining data. The historical reason was that reanalysis data used to be available only 4 times per day. Such a frequency, on the other hand, can be insufficient for capturing fast variations because of the problem of aliasing.

Figure 3 shows the evolution of lower-troposphere $(700 \mathrm{hPa})$ zonal wind and temperature averaged over the Peruvian stratocumulus region marked by the red box in Fig. 2e, for a 2-day period starting from $00 \mathrm{Z} 02$ in January 2010. In Fig. 3, the black solid lines are time-step-by-time-step output from CLIM where $\Delta t=30 \mathrm{~min}$. The dashed lines are the linearly interpolated time series used in the calculation of nudging tendencies; green, blue, and red correspond to cases in which the constraining data was provided at $1 \mathrm{~h}, 3 \mathrm{~h}$, and $6 \mathrm{~h}$ frequencies, respectively. The EAMv1-simulated wind field in the Peruvian stratocumulus region shows prominent $12 \mathrm{~h}$ cycles. Linear interpolation of 6-hourly data misses all the local maxima and minima (red line in Fig. 3a) while the interpolation from 3-hourly data provides substantial improvements (blue line in Fig. 3a). The temperature time series in Fig. $3 \mathrm{~b}$ also shows $12 \mathrm{~h}$ variations although the amplitude is much smaller compared to the diurnal cycle. 
https://doi.org/10.5194/gmd-2022-10

Preprint. Discussion started: 3 February 2022

(c) Author(s) 2022. CC BY 4.0 License.

(c) (i)

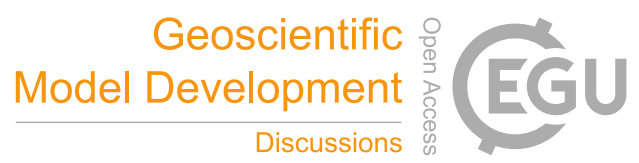

Considering the multiscale nature of the atmospheric motions, one can speculate there are modes of variability that need higher than 3-hourly sampling frequency to avoid aliasing. The sensitivity experiments conducted using $6 \mathrm{~h}, 3 \mathrm{~h}$, and $1 \mathrm{~h}$ constraining data (cf. group 2 of Table 1 and Fig. 4), however, suggest that nudged simulations using 3-hourly data can provide annual mean cloud forcing estimates that agree with CLIM within $1 \mathrm{~W} \mathrm{~m}^{-2}$ for most grid cells.
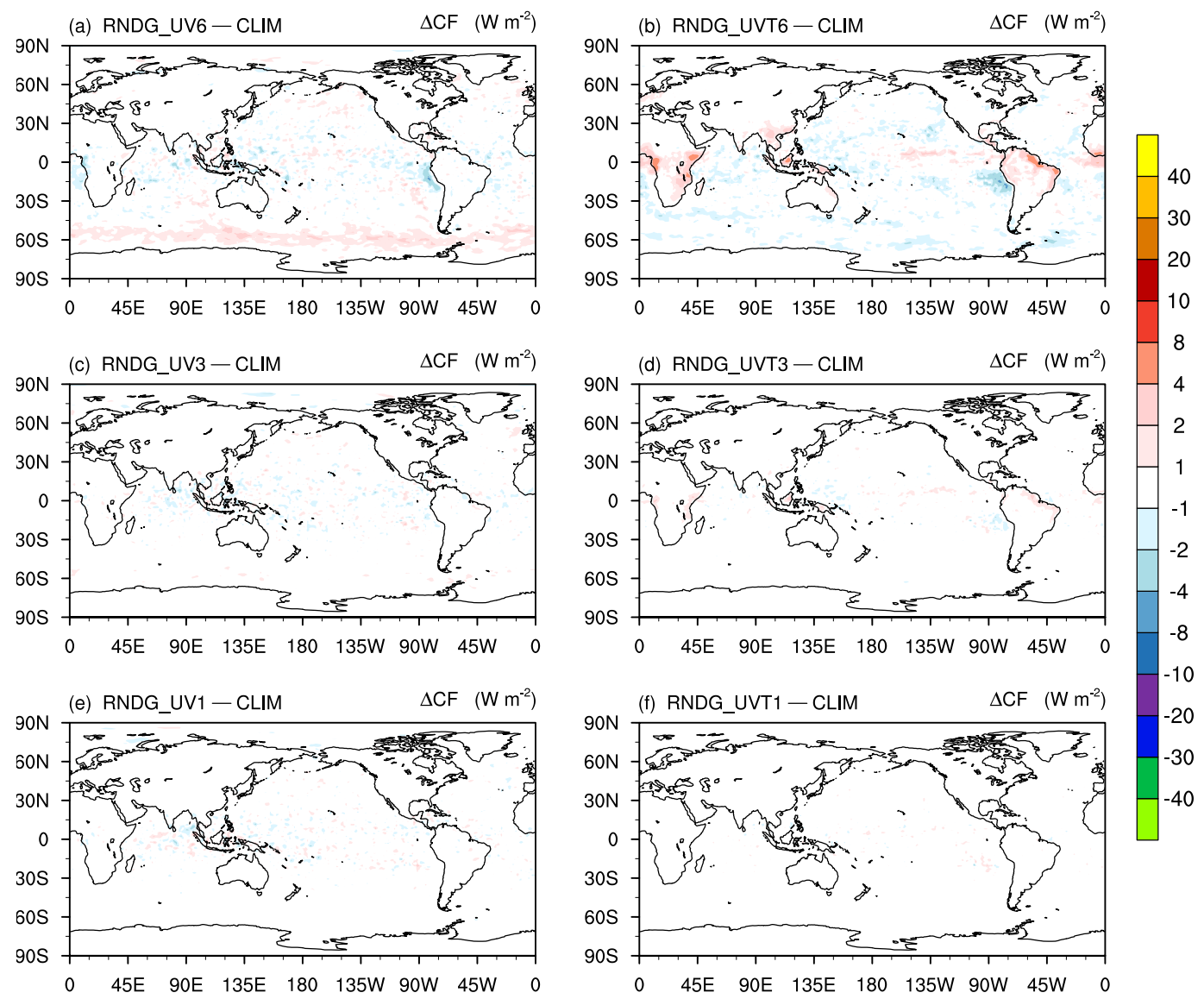

Figure 4. Differences in annual mean total cloud forcing $\left(\Delta \mathrm{CF}\right.$, unit: $\left.\mathrm{W} \mathrm{m}^{-2}\right)$ between nudged simulations and CLIM. Simulations shown in the left column used only wind nudging while simulations shown in the right column used wind and temperature nudging. From the first row to the bottom row, the frequency of constraining data used in the nudged simulation is 6-hourly, 3-hourly, and hourly, respectively. The simulation setups are described in Section 2.3 and Table 1.

\subsection{Climate representativeness beyond cloud radiative forcing}

The investigations discussed in Sections 3.1 and 3.2 focused on cloud radiative forcing. In Fig. 5, we further evaluate the climate representativeness of the nudged simulations by assessing the annual averages of twenty $2 \mathrm{D}$ fields that are often examined during model development and tuning. For each nudged simulation in group 2 of Table 1 and each of the twenty fields, we 
(a) Relative difference in global mean

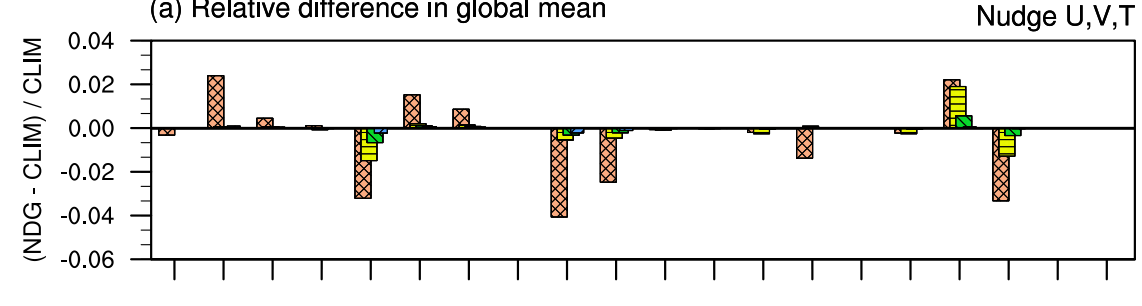

(b) Relative difference in global mean

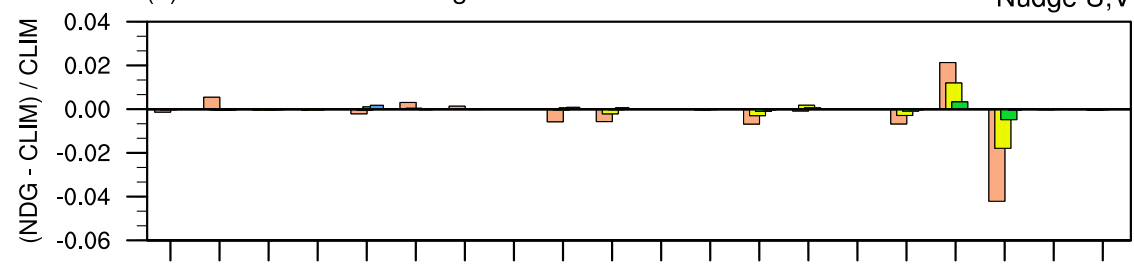

(c) Relative difference in global pattern

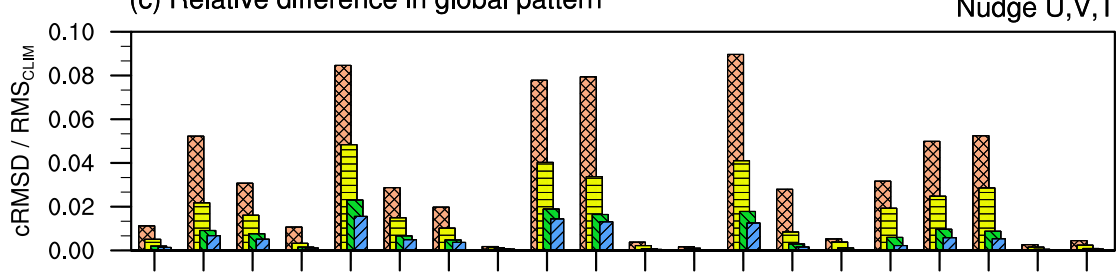

(d) Relative difference in global pattern

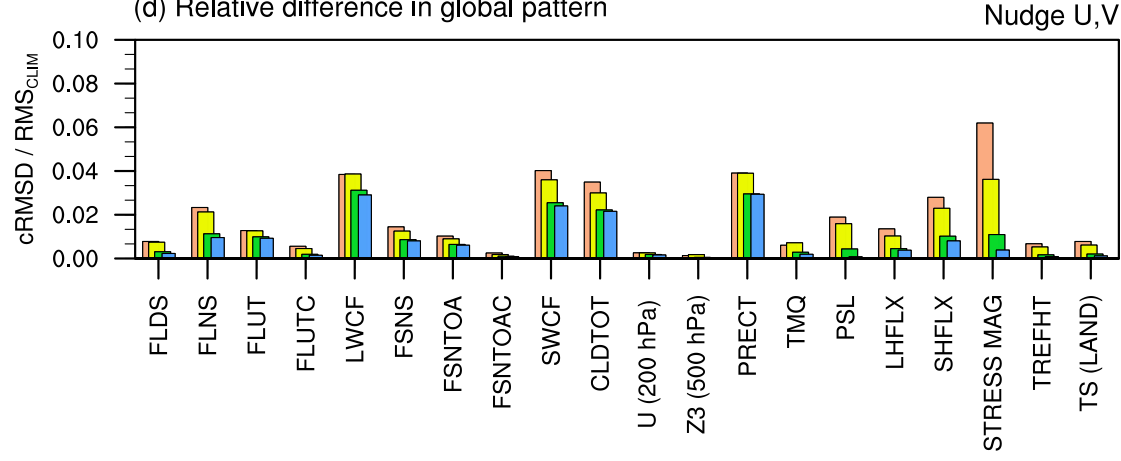

DNDG_UVT6

$\sqsupseteq$ RNDG_UVT6

RNDG_UVT3

DIS RNG_UVT1

$\square$ DNDG_UV6

$\square$ RNDG_UV6

$\square$ RNDG_UV3

$\square$ RNDG_UV1

DNDG_UVT6

$\Longrightarrow$ RNDG_UVT6

RNDG_UVT3

E RNDG_UVT1

$\square$ DNDG_UV6

$\square$ RNDG_UV6

$\square$ RNDG_UV3

$\square$ RNDG_UV1

Figure 5. Comparison of annual averages in nudged simulations and CLIM. The physical quantities labeled along the $\mathrm{x}$-axis are explained in Table A2. Panels (a) and (b) show relative differences in the simulated global averages. Panels (c) and (d) show relative differences in the simulated geographical distributions. The hatched bars shown in panels (a) and (c) correspond to simulations using wind and temperature nudging; the bars without hatching shown in panels (b) and (d) correspond to simulations using wind-only nudging. Different colors in the same panel indicate different nudging configuration (sequence of calculation and frequency of constraining data). All differences were calculated against CLIM. Further details can be found in Section 3.3 and Appendix A2. 
https://doi.org/10.5194/gmd-2022-10

Preprint. Discussion started: 3 February 2022

(C) Author(s) 2022. CC BY 4.0 License.

(c) (i)

calculated two error metrics with respect to CLIM: one measuring the difference in the global annual mean (Fig. 5a-b) and one measuring the root-mean-square difference in the annually averaged global geographical pattern (Fig. 5c-d, cf. Appendix A2).

Consistent with the cloud forcing results shown in Figures 2 and 4, the revised sequence of calculation and $3 \mathrm{~h}$ data frequency have larger impacts on the UVT-nudged simulations than on UV-nudged simulations. Nevertheless, we see a systematic reduction of global mean and pattern errors across all twenty quantities evaluated in Fig. 5. In simulations RNDG_UVT3 and RNDG_UV3, the errors in global averages are reduced to less than $1 \%$. The errors in geographical patterns are reduced to $2 \%$ or less for the UVT-nudged simulation and $3 \%$ or less for the UV-nudged simulation (the lower error associated with UVT-nudging is likely an indication of better consistency between winds and temperature). Further increase of data frequency

215 to $1 \mathrm{~h}$ only leads to limited improvements in the simulated geographical patterns. In addition, we consistently see the fact that increasing data frequency from 6-hourly to 3-hourly leads to a better agreement of global averages with the free-running simulation, but a further increase to hourly data no longer lead to substantial differences (cf. Table S2).

Therefore, for future applications that use simulations nudged to the model's own meteorology, we recommend using the revised sequence of calculation depicted in Fig. $1 \mathrm{~b}$ and 3-hourly constraining data. UV-nudging and UVT-nudging can give similar results, with the former providing slightly better internal consistency.

\section{Evaluation of simulations nudged to reanalyses}

As mentioned in the introduction, a common application of nudging is to force the simulated large-scale meteorological conditions to follow the trajectory of the observed evolution so as to facilitate process-level model evaluation or composite analyses focused on specific types of weather events. In this case, nudged simulations are typically performed using gridded reanalysis products from an operational weather prediction center as the constraining data. The findings from the previous section, especially the conclusion that higher frequency of the constraining data might help better capture important modes of variability, motivated us to evaluate the potential benefits of using more recent reanalysis products such as ERA5 (Hersbach et al., 2020) and MERRA2 (Gelaro et al., 2017). Since ERA5 has the highest data frequency (i.e., hourly), and ERA5 is also known to show better agreement with observations when compared with its predecessor ERA-Interim (Hersbach et al., 2020), we focus on ERA5-constrained simulations in this section and use the sensitivity experiments listed in group 3 of Table 1 to answer the following questions:

- What is the impact of nudging on the simulated mean climate? (Section 4.1)

- Do ERA5-nudged hindcast simulations agree better with observations than the ERA-Interim-nudged simulations? (Section 4.2)

- How frequently should the nudging data be provided to obtain sufficiently good hindcast skill? (Section 4.3) 

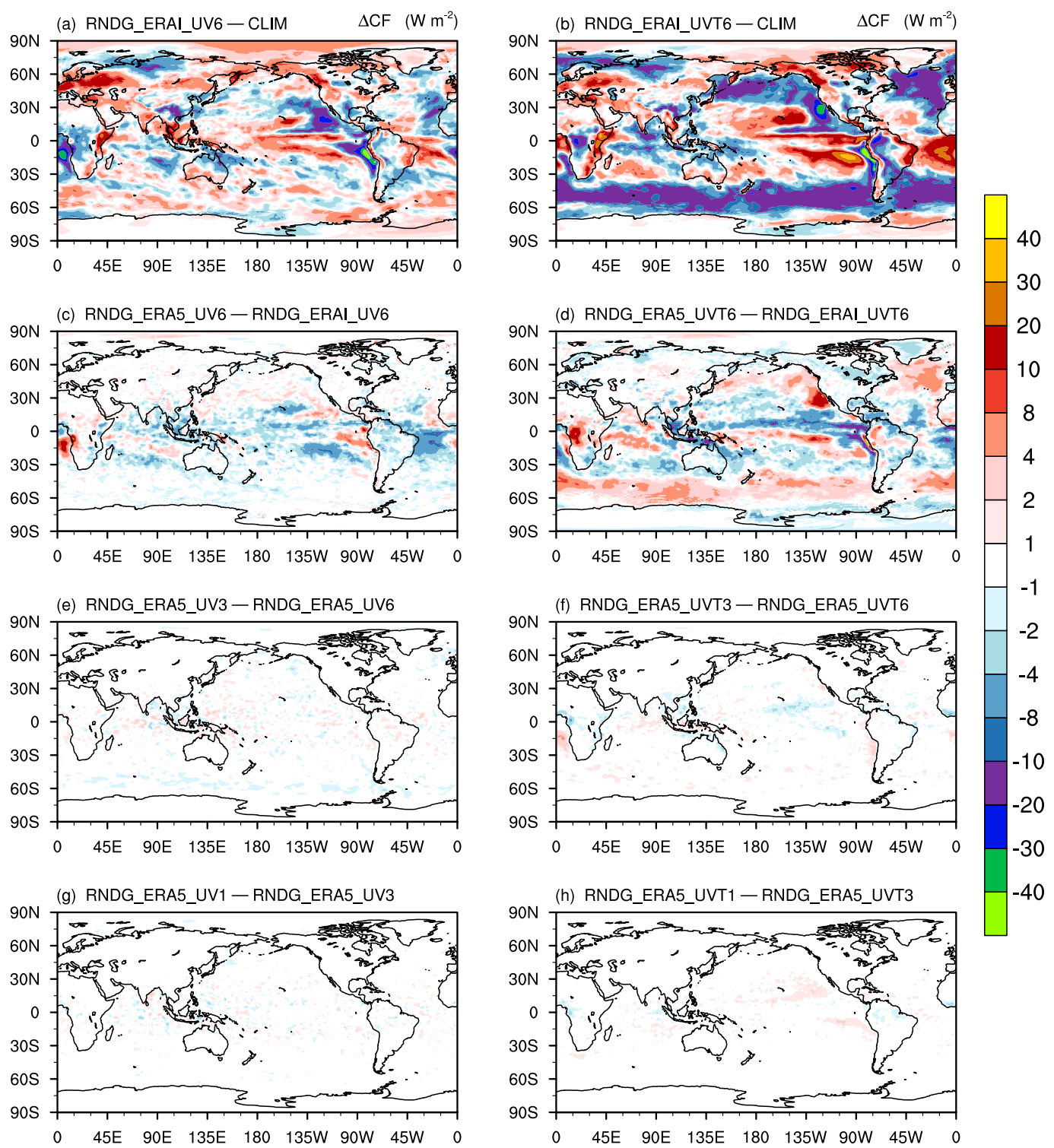

Figure 6. Annual mean differences in total cloud forcing ( $\triangle \mathrm{CF}$, unit: $\mathrm{W} \mathrm{m}^{-2}$ ). The top row shows differences between simulations nudged to ERA-Interim and without nudging (CLIM). The second row shows differences between simulations nudged to ERA5 and ERA-Interim, both using 6-hourly constraining data temporally interpolated to every model time step. The third (fourth) row shows the differences between simulations that interpolate 3-hourly (1-hourly) versus 6-hourly reanalysis data to constrain the model simulated meteorology. The left and right columns correspond to wind-only nudging and wind-and-temperature nudging, respectively. Details of the simulation setup can be found in Section 2.3 and Table 1. 
https://doi.org/10.5194/gmd-2022-10

Preprint. Discussion started: 3 February 2022

(c) Author(s) 2022. CC BY 4.0 License.

\section{(c) (i)}

\subsection{Global and regional mean climate}

Since the long-term climate simulated by the free-running EAMv1 is known to have non-negligible biases with respect to observational data (Rasch et al., 2019; Xie et al., 2018), nudging towards reanalysis is expected to result in significant changes in the statistical features of the simulated climate. When $\mathrm{U}$ and $\mathrm{V}$ are nudged to 6-hourly meteorology from ERA-Interim, the annual mean total CF can deviate from CLIM by more than $-20 \mathrm{~W} \mathrm{~m}^{-2}$ in the Californian, Peruvian, and Namibian stratocumulus regions. When $\mathrm{T}$ is also nudged, we see deviations on the order of $-10 \mathrm{~W} \mathrm{~m}^{-2}$ to $-20 \mathrm{~W} \mathrm{~m}^{-2}$ over the storm tracks and $10 \mathrm{~W} \mathrm{~m}^{-2}$ to $40 \mathrm{~W} \mathrm{~m}^{-2}$ over the trade cumulus regions (Figure 6, first row). Noticeable changes in the global mean CF are also evidenced in the ERA-nudged simulations with UVT nudging, the deviations from CLIM are on the order of -1 to $-2 \mathrm{~W} \mathrm{~m}^{-2}$ (cf. Table S2). These results are consistent with Sun et al. (2019) that ERA-nudged runs differ substantially from CLIM.

The second row of Figure 6 shows the impact of using ERA5 instead of ERA-Interim while keeping a 6-hourly data frequency. The resulting changes are substantially smaller than the differences between ERA-nudged simulations and CLIM, although we still see some CF differences in the subtropics and tropics as large as $10 \mathrm{~W} \mathrm{~m}^{-2}$ to $20 \mathrm{~W} \mathrm{~m}^{-2}$. The relatively small impact of replacing ERA-Interim by ERA5 is expected, as the differences between ERA5 and ERA-Interim are substantially smaller than the differences between either reanalysis and the free-running EAMv1 simulations. (As an example, the annual mean zonal mean pressure-latitude cross-section of air temperature differences are shown in Fig. A3). Increasing the data frequency from 6-hourly to 3-hourly can lead to local changes of 1 to $4 \mathrm{~W} \mathrm{~m}^{-2}$ in CF. These magnitudes are similar to what we have seen in Fig. 4a-d for the simulations nudged to CLIM. Further increasing the data frequency to hourly only introduces negligible changes, again similar to what we have seen in simulations nudged to CLIM (Fig. 4e-f).

A large number of model output variables have been examined in addition to CF, where we consistently see the differences between ERA-Interim-nudged and ERA5 nudged simulations being substantially smaller than the differences between nudged runs and CLIM, although the magnitudes are non-negligible in some regions. We also consistently see the fact that increasing data frequency from 6-hourly to 3-hourly can lead to discernible changes locally while a further increase to hourly data no longer lead to substantial differences. The impacts on global averages are generally very small (cf. Table S2).

\subsection{Global and regional weather events}

To evaluate the simulation of large-scale weather events, we follow the procedure used for Figure 5 in Sun et al. (2019) and examine the anomaly correlation between nudged simulations and observations. Here, an anomaly is defined as the deviation of a simulated or observed quantity from the corresponding (simulated or observed) monthly average at the same geographical location. We first examined the anomaly correlation between the nudged simulations and the corresponding reanalysis (ERAInterim or ERA5) for temperature, specific humidity, as well as horizontal and vertical winds at various pressure levels. The results were found to be very similar to those presented in Figure 5 in Sun et al. (2019). ERA-Interim and ERA5 nudged simulations show similar correlations to the corresponding reanalyses (c.f. Figure S1). 
(a) Spatial correlation
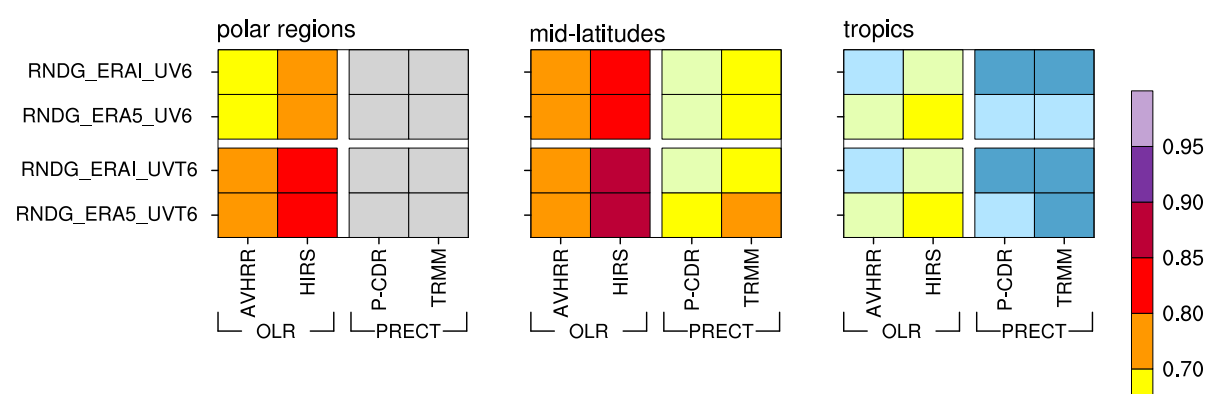

(b) Temporal correlation
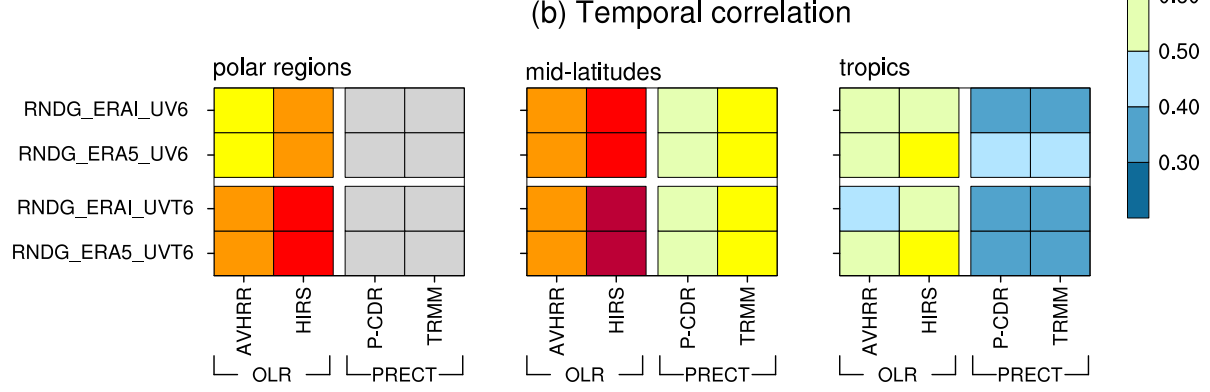

Figure 7. Anomaly correlation between simulated and observed OLR and precipitation: (a) annual mean spatial correlation; (b) spatially averaged temporal correlation. Different rows correspond to different nudged simulations. Different latitude bands are examined separately: polar regions $\left(60-90^{\circ} \mathrm{S}, 60-90^{\circ} \mathrm{N}\right)$, midlatitudes $\left(30-60^{\circ} \mathrm{S}, 30-60^{\circ} \mathrm{N}\right)$, and tropics $\left(20^{\circ} \mathrm{S}-20^{\circ} \mathrm{N}\right)$. The physical quantities and sources of observational data are indicated below the heat maps. All correlations were calculated from anomalies with respect to monthly averages. Gray boxes indicate missing values resulting from observational data being unavailable. The simulation setups are described in Section 2.3 and Table 1.

Since the discussion in this section focuses on comparing the hindcast skill of the ERA-Interim-nudged and ERA5-nudged simulations, we present in Figs. 7 and 8 an evaluation against global and regional-scale satellite retrievals of outgoing longwave radiation (OLR) and surface precipitation rate. Panel (a) in each figure shows the annual average of spatial correlations in different latitude bands; panel (b) in each figure shows the spatially averaged temporal correlations the anomalies. In Fig. 7, the two upper rows in each panel compare simulations ERA-Interim-nudged and ERA5-nudged that used wind-only nudging and the lower rows compare simulations that also used temperature nudging. Figure 8 compares ERA5-nudged simulations that used different data frequencies. The EAM-simulated OLR is compared with National Oceanic and Atmospheric Administration's (NOAA's) daily retrievals from the High Resolution Infrared Radiation Sounder (Lee et al., 2007, HIRS) and the Advanced Very High Resolution Radiometer (AVHRR; Stowe et al., 2002). The simulated total precipitation rate is compared with 3-hourly data from the Tropical Rainfall Measuring Mission (TRMM) 3B42V7 product (Huffman et al., 2007; Huffman and Bolvin, 2013) and daily data from the Precipitation Estimation from Remotely Sensed Information using Artificial Neural 

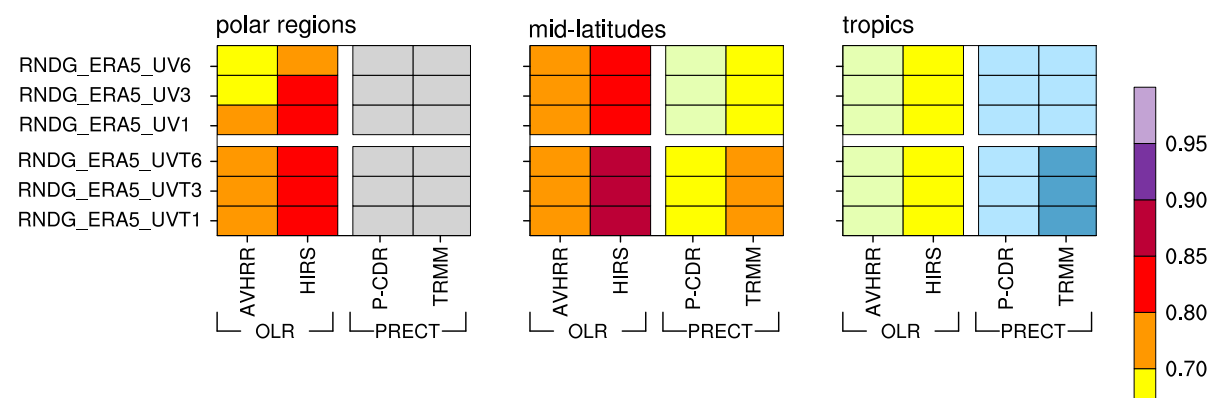

(b) Temporal correlation
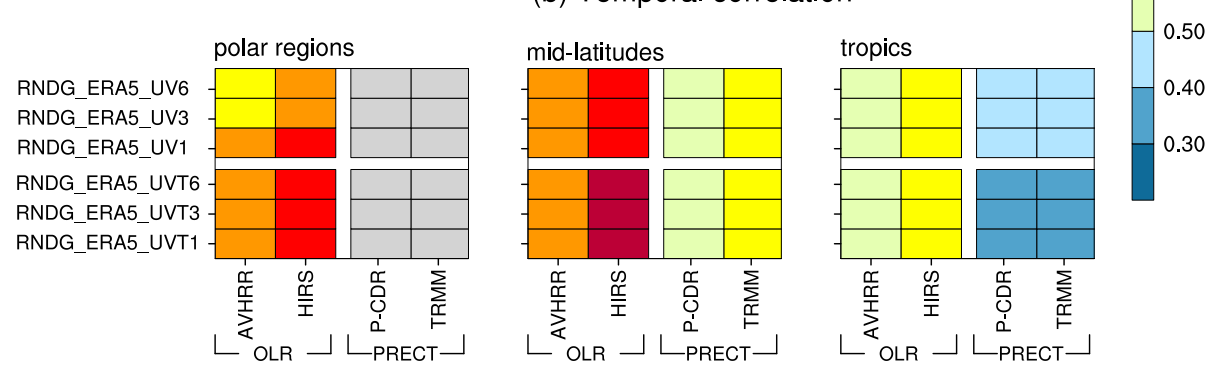

Figure 8. Similar to Fig. 7 but for simulations using different data frequencies (6-hourly, 3-hourly, or hourly). All simulations shown in this figure were nudged to the ERA5 reanalysis. Simulations shown in the top three rows of (a) and (b) used the wind-only (U, V) nudging, while simulations shown in the bottom three rows of (a) and (b) used the wind and temperature (U, V, and T) nudging.

Networks-Climate Data Record (labeled as "P-CDR" in figures here, Ashouri et al., 2015). Further details of the datasets and the comparison procedure can be found in Sun et al. (2019).

The anomaly correlations shown in Fig. 7 indicate that the correlations in the high- and mid-latitude regions are very similar between the ERA5 and ERA-Interim nudged simulations regardless of whether temperature is constrained. In the low latitudes $\left(20^{\circ} \mathrm{S}\right.$ to $\left.20^{\circ} \mathrm{N}\right)$, the correlations are higher when ERA5 is used as the constraining data, in terms of both OLR and precipitation, and both with or without temperature nudging. Figure 8 indicates that the changes associated with higher data frequency are small for the annual or regional averages shown here.

Figure 9 evaluates the simulated zonal and temporal propagation of meridionally averaged precipitation rate in boreal spring (March to May) of 2010 over the tropical Pacific Ocean $\left(10^{\circ} \mathrm{S}-10^{\circ} \mathrm{N}, 60^{\circ} \mathrm{E}-90^{\circ} \mathrm{W}\right.$, upper row) and North America $\left(25^{\circ} \mathrm{N}-\right.$ $50^{\circ} \mathrm{N}, 150^{\circ} \mathrm{E}-60^{\circ} \mathrm{W}$, lower row). Panels (a) and (d) are Hovmöller diagrams plotted from the TRMM data. The bar charts show the correlation between the Hovmöller diagram of TRMM data and the corresponding Hovmöller diagrams plotted from various nudged simulations. Consistent with the anomaly correlations shown in Figs. 7 and 8, in the tropics we see a clear improvement in the simulated propagation of precipitation when ERA5 is used as the constraining data (Fig. 9b) while in the mid-latitudes there are no substantial differences between ERA-Interim-nudged and ERA5-nudged results (Fig. 9e). The 
(a) TRMM $\left(10^{\circ} \mathrm{S}-10^{\circ} \mathrm{N}\right)$

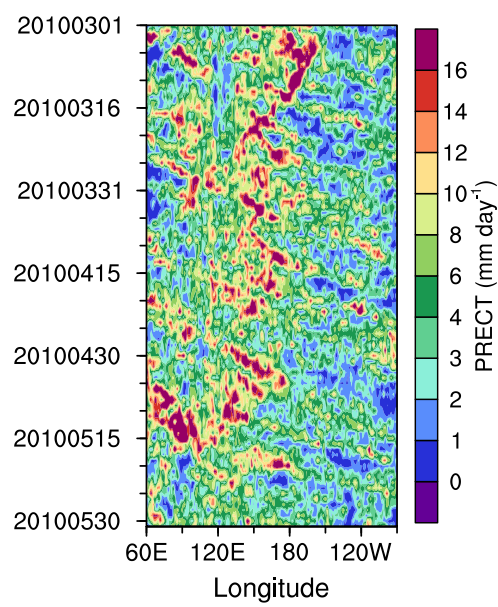

(d) TRMM $\left(25^{\circ} \mathrm{N}-50^{\circ} \mathrm{N}\right)$

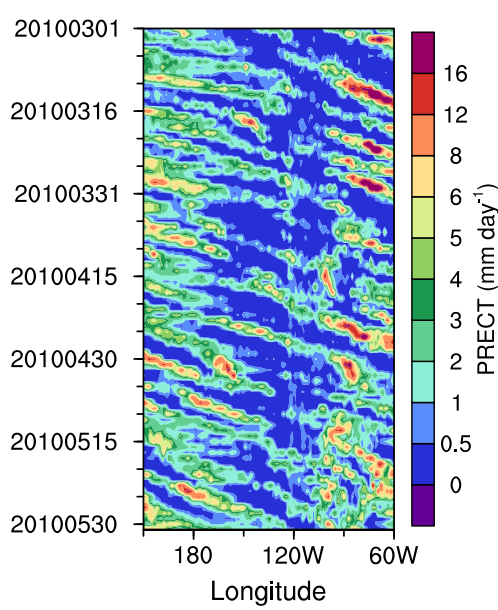

(b) Nudged to ERAI or ERA5

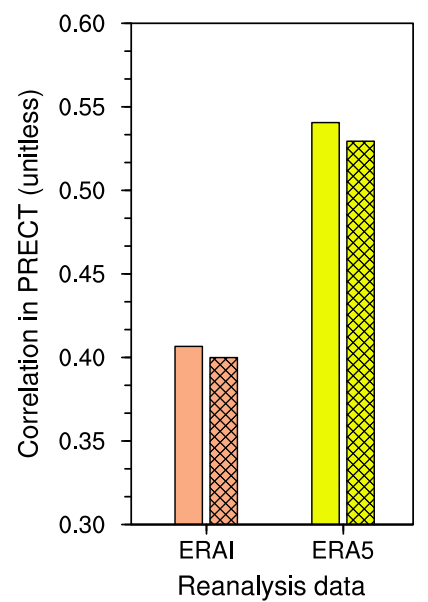

(e) Nudged to ERAI or ERA5

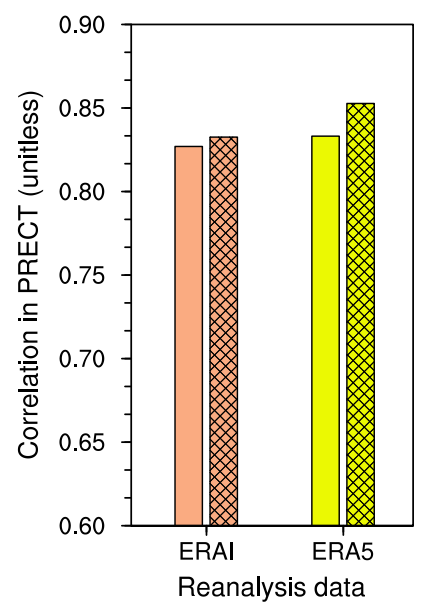

(c) Nudged to ERA5

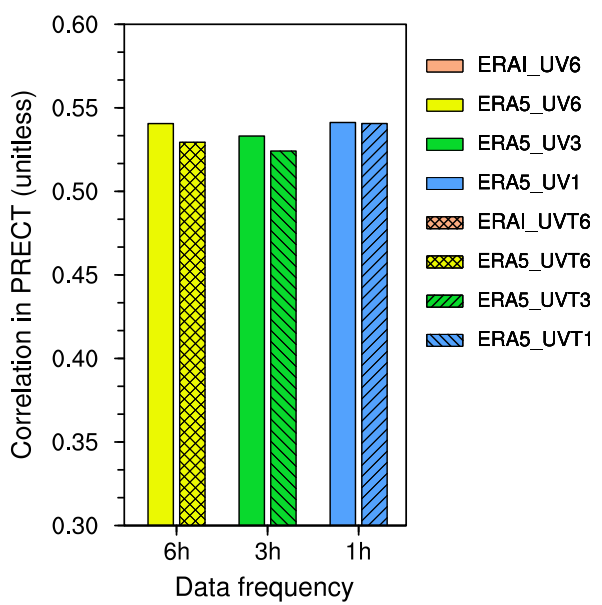

(f) Nudged to ERA5

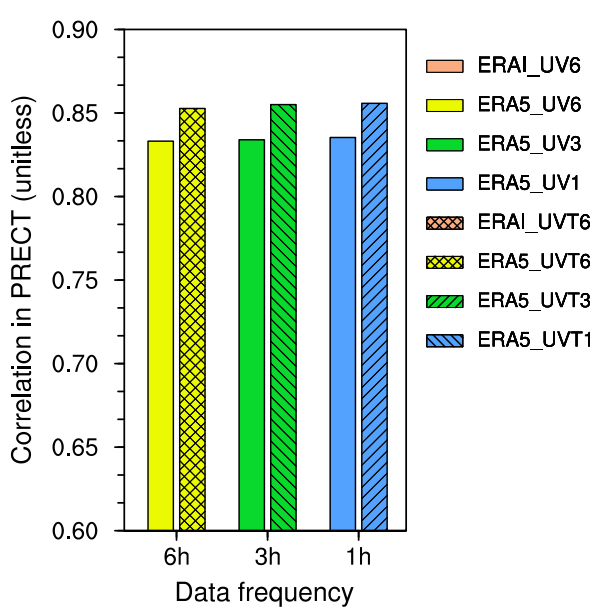

Figure 9. Evaluation of the spatio-temporal distribution of daily precipitation from 1 March to 31 May 2010 over the tropical Pacific Ocean $\left(10^{\circ} \mathrm{S}-10^{\circ} \mathrm{N}, 60^{\circ} \mathrm{E}-90^{\circ} \mathrm{W}\right.$, upper row) and North America $\left(25^{\circ} \mathrm{N}-50^{\circ} \mathrm{N}, 150^{\circ} \mathrm{E}-60^{\circ} \mathrm{W}\right.$, lower row). (a) and (d): Hovmöller diagram of the meridionally averaged total precipitation rates (PRECT, unit: $\mathrm{mm}_{\text {day }}{ }^{-1}$ ) from TRMM. The dates are labeled along the y axis. (b-c) and (e-f): correlations between a Hovmöller diagram derived from TRMM and the Hovmöller diagram derived from various nudged simulations. Panels (b) and (e) compare simulations using ERA-Interim or ERA5 as constraining data and with or without temperature nudging. Panels (c) and (f) compare simulations with U,V or U, V, and T nudged towards ERA5 but using 6-hourly, 3-hourly, and hourly reanalysis for the constraining data. All nudged simulations shown here used the sequence of calculation in Fig. 1b, so the prefix "RNDG_" is dropped to keep the legends short. The simulation setups are described in Section 2.3 and Table 1. 
https://doi.org/10.5194/gmd-2022-10

Preprint. Discussion started: 3 February 2022

(C) Author(s) 2022. CC BY 4.0 License.

\section{(c) (i)}

impact of frequency of the constraining data is negligible (Fig. 9c, f). Same conclusions can be drawn if we use root-mean-squre error (RMSE) as the evaluation metrics (c.f. Figure A4), and if we change the evaluation to a different season (c.f. Figure S2).

As an aside, we note that the better precipitation hindcast skills in the mid-latitudes than in the tropics (Fig. 9c versus d) are consistent with the findings in Sun et al. (2019). The impact of constraining temperature appear to be negligible for the 2010 results shown here (Fig. 9c-d, solid fill versus hatching), while Sun et al. (2019) showed better precipitation hindcast skill with additional temperature nudging for spring 2011, especially in the tropics (see Figures 6 and 7 therein). This suggests that the role of temperature nudging can be case dependent. Future evaluation in this aspect will be useful.

\subsection{Comparison with the ARM observations}

To further assess the hindcast skill of the nudged simulations, we use the radiosonde observations collected by the US Department of Energy's Atmospheric Radiation Measurement (ARM) user facility. Radiosonde data are often considered to be reliable high-accuracy measurements (Milrad, 2017) and therefore can provide an objective evaluation of model simulations. Data from three ARM atmospheric observatories are selected to cover different climate regimes, including the Southern Great Plains (SGP) site over the mid-latitude land (https://www.arm.gov/capabilities/observatories/sgp), the North Slope of Alaska (NSA) site in the NH polar region (https://www.arm.gov/capabilities/observatories/nsa), and the Tropical Western Pacific site at Manus (TWPC1), Nauru (TWPC2), and Darwin (TWPC3) in the tropics (https://www.arm.gov/capabilities/observatories/twp). To our knowledge, radiosonde measurements from these sites were not used in the data assimilation system producing the ERA reanalysis products, and hence can be considered to be independent data for the evaluation of the simulations nudged to ERAInterim or ERA5.

The simulated temperature, relative humidity, and horizontal wind speeds for January 2010 are evaluated against measurements collected at SGP (Fig. 10a-d), NSA (Fig. 10e-h), and three TWP sites (TWPC1 in Fig. 11a-d, TWPC2 in Fig. 11e-h, and TWPC3 in Fig. 11i-1) from the same time period. The ERA-Interim reanalysis (black dashed lines in the figures) and ERA5 (black solid lines) are also included for comparison. The 6-hourly model output and reanalysis products were horizontally remapped to the location of ARM site using bilinear interpolation. For each of the meteorological quantities shown here, the root-mean-square error (RMSE) between ERA-nudged simulations (or ERA analyses) and the ARM measurements were calculated with all available vertical profiles at each site in January 2010. The number of vertical profiles for each field at SGP, NSA, TWPC1, TWPC2 and TWPC 3 is 121, 63, 49, 57 and 127, respectively (ARM observatories provide data four times a day at SGP and TWPC3, and twice a day at the NSA, TWPC1 and TWPC2). The temporal correlations between EAM simulations or ERA analyses and the ARM measurements are shown in Fig. A5 and Fig. A6 in the Appendix.

As expected, reanalyses (black lines in Fig. 10, Fig. 11, Fig. A5 and Fig. A6 ) show better agreement with the ARM radiosonde data compared to the nudged EAM simulations (colored lines). ERA5 (solid black in Fig. 10 and Fig. A5) is in general better than ERA-Interim (dashed black) at the mid-latitude SGP site and the high-latitude NSA site. For the three ARM TWP sites in the tropics, ERA5 is not necessarily better than ERA-Interim. For example, ERA5 zonal wind field (U, solid black in Fig. 10d) shows larger RMSEs below $500 \mathrm{hPa}$ compared to the ERA-Interim (dashed black). 

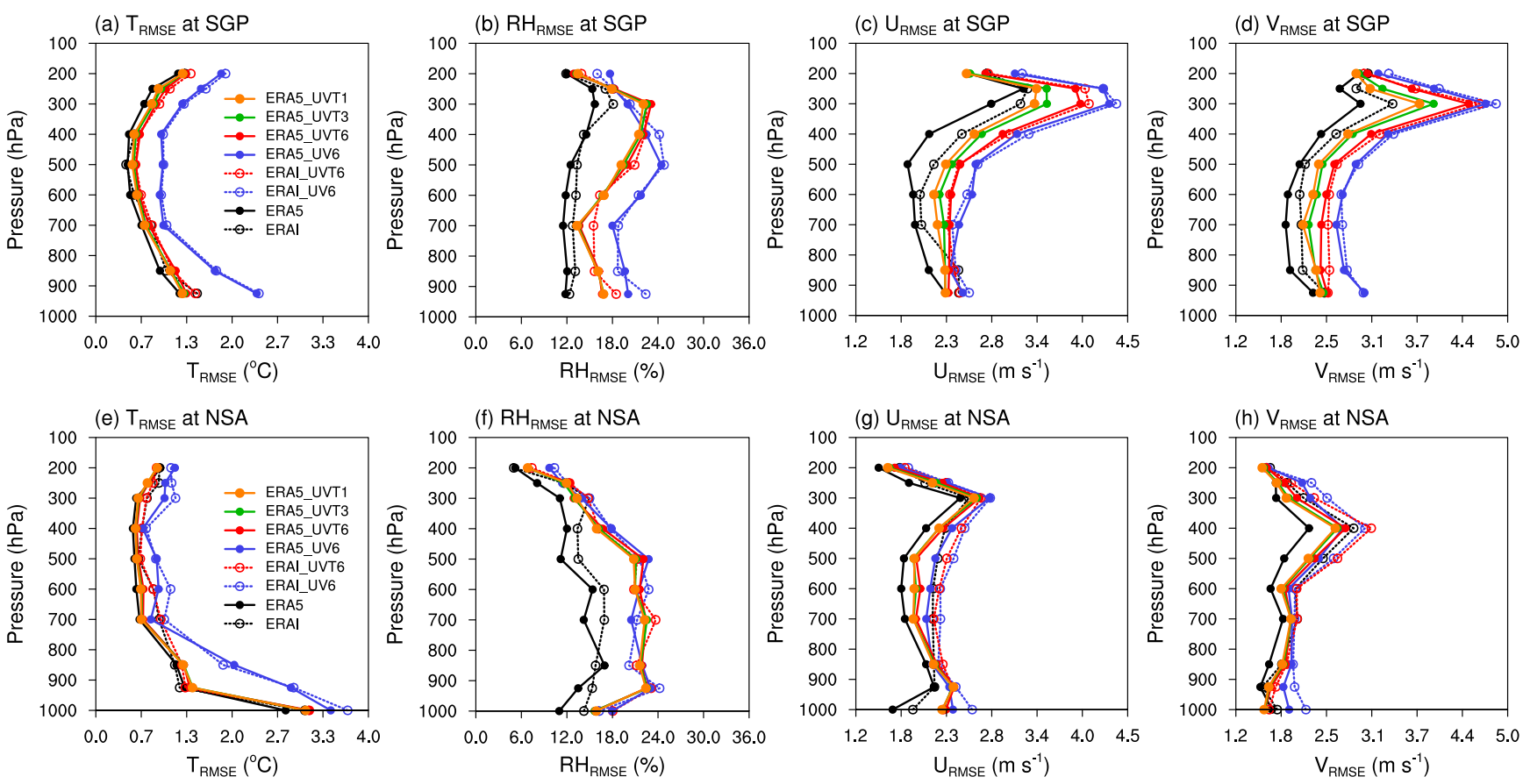

Figure 10. Comparison of two reanalysis products (ERA-Interim and ERA5, black lines) and various nudged simulations (colored lines) with ARM radiosonde measurements of January 2010 at the location of Southern Great Plains (SGP) $\left(36.607^{\circ} \mathrm{N}, 97.488^{\circ} \mathrm{W}\right.$; panels a-d), and North Slope of Alaska (NSA) $\left(71.323^{\circ} \mathrm{N}, 156.609^{\circ} \mathrm{W}\right.$; panels e-h), The four columns from left to right show the root-mean-square error (RMSE) in temperature (T, unit: $\left.{ }^{\circ} \mathrm{C}\right)$, relative humidity (RH, unit: percent), zonal wind (U, unit: $\mathrm{m} \mathrm{s}^{-1}$ ) and meridional wind (V, unit: $\mathrm{m} \mathrm{s}^{-1}$ ). All nudged simulations shown here used the sequence of calculation in Fig. 1b, so the prefix "RNDG_" is dropped in this figure to keep the labels short. The simulation setups can be found in Section 2.3 and Table 1. RMSEs were calculated from 6-hourly data for ARM SGP (121 profiles per variable) and 12-hourly data for ARM NSA (63 profiles per variable) in January 2010. We note that the radiosonde observation only samples twice per day at ARM NSA site. Bilinear interpolation was used to remap the reanalyses and model output to the two ARM sites.

The ERA-nudged simulations show good agreement with the ARM radiosonde measurements at the mid-latitude (SGP) and high-latitude (NSA) sites (Fig. 10). Compared to the ERA-Interim-nudged simulations (colored dashed lines), the ERA5nudged simulations (colored solid lines) produce slightly better hindcast skills. In addition, EAM simulations with temperature nudging (red, orange and green lines) show overall better hindcast skills, regardless of which ERA product was used as the constraining data. Slightly better hindcast skills for horizontal winds can be obtained by using the 3-hourly ERA5 data (green lines) for nudging, instead of using the 6-hourly data (red lines). Using 3-hourly (green lines) or hourly (orange lines) constraining data gives very similar results.

Consistent with the experiences reported in the literature (e.g., Jeuken et al., 1996; Sun et al., 2019), weather events in the tropics are less well constrained by nudging. Compared to the ARM SGP and NSA sites (Fig. 10, Fig. A5), the magnitude of the RMSEs in ERA-nudged simulation at three ARM TWP sites are in a similar range (Fig. 11), while the temporal correlations 
are smaller, especially for temperature and relative humidity (Fig. A6). In addition, the differences of RMSEs and temporal correlations in ERA-nudged simulations with ERA5 reanalysis and higher constraining data frequency are not obvious at the three ARM TWP sites, except that EAM simulations with UVT nudging (red, orange and green lines in Fig. 11 and Fig. A6) still show consistent better hindcast skills than the UV nudging (blue lines).
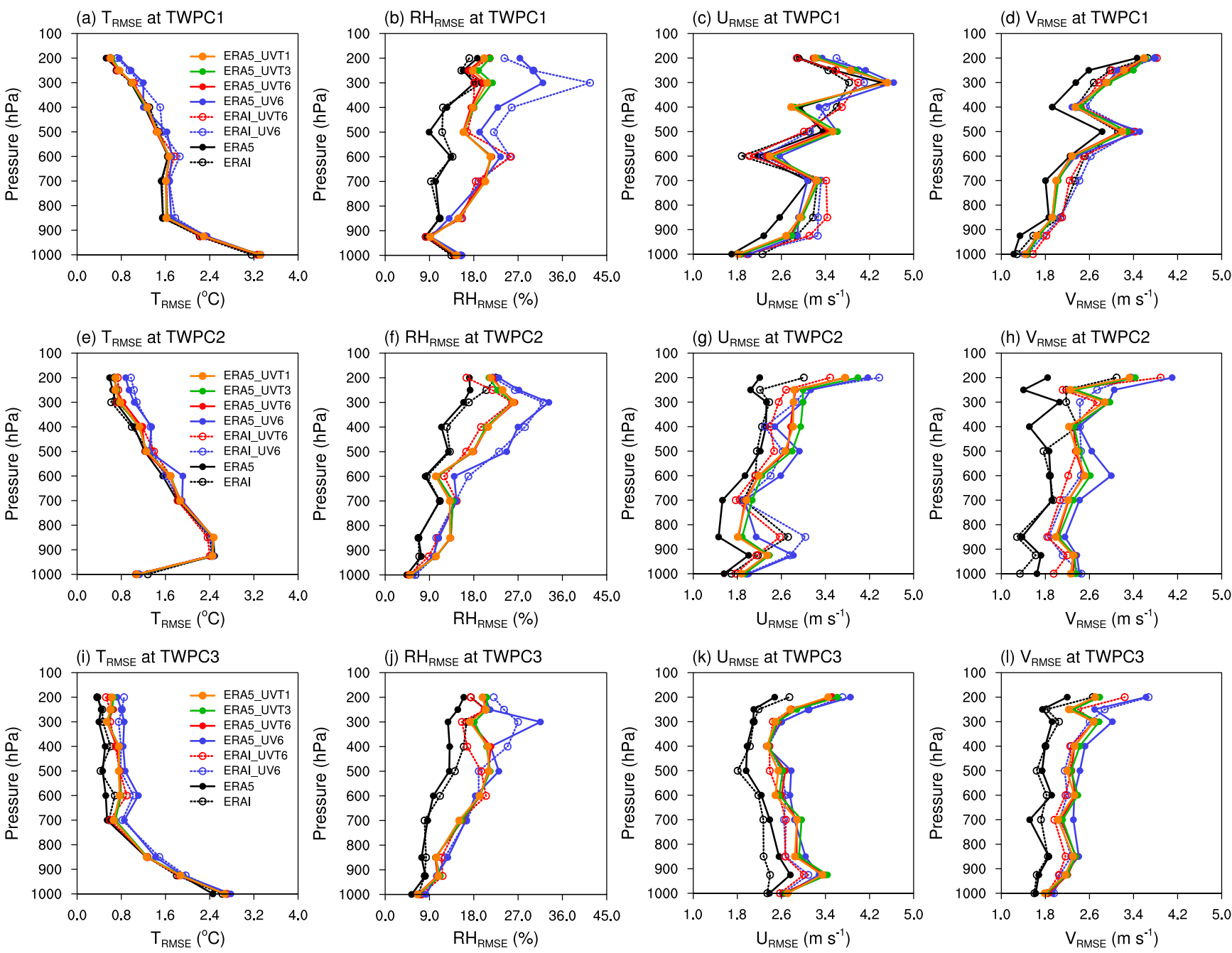

Figure 11. As in Fig. 10 but showing the root-mean-square-errors (RMSEs) at the location of Tropical Western Pacific (TWP) site at Manus $\left(2.060^{\circ} \mathrm{S}, 147.425^{\circ} \mathrm{E}\right.$; panels a-d), Nauru (0.502 ${ }^{\circ} \mathrm{S}, 166.917^{\circ} \mathrm{E}$; panels e-h), and Darwin $\left(12.425^{\circ} \mathrm{S}, 130.892^{\circ} \mathrm{E}\right)$; panels i-1). The simulation setups can be found in Section 2.3 and Table 1. RMSEs were calculated from 12-hourly data for ARM TWP1 (49 profiles per variable) and TWPC2 (57 profiles per variable), and 6-hourly data for TWPC3 (127 profiles per variable) in January 2010. We note that the radiosonde observation only samples twice per day at ARM TWPC1 and TWPC2, and four time per day at TWPC3. Bilinear interpolation was used to remap the reanalyses and model output to the three ARM sites. 
https://doi.org/10.5194/gmd-2022-10

Preprint. Discussion started: 3 February 2022

(c) Author(s) 2022. CC BY 4.0 License.

\section{(c) (i)}

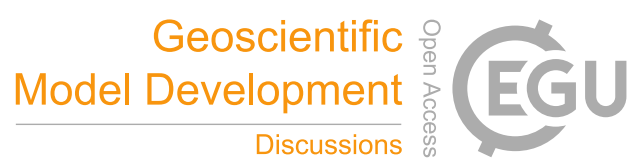

\section{Impact on the estimation of anthropogenic aerosol effect}

Nudging has been recognized as a useful and computationally efficient technique for estimating the anthropogenic aerosol effect $\left(\mathrm{F}_{a e r}\right)$ in global climate models (Kooperman et al., 2012; Zhang et al., 2014, 2016; Ghan et al., 2016; Liu et al., 2018). In this section, we evaluate the impact of nudging implementation on the estimated anthropogenic aerosol effect in EAM, as it has been identified as one of the key aspects that need more attention in the future development and evaluation of EAM (Golaz et al., 2019; Zhang et al., 2022). As mentioned in Section 2.3, a subset of the nudging configurations listed in Table 1 are used to conduct simulations with both the present-day (PD, year 2010) and pre-industrial (PI, year 1850) emissions of anthropogenic aerosols and their precursors to estimate $\mathrm{F}_{\text {aer }}$.

Figure 12a-b shows the globally averaged annual mean PD-PI differences in the top-of-atmosphere (TOA) radiation fluxes and cloud radiative effects. Results from the nudged simulations are normalized by the corresponding values derived from CLIM (ensemble mean). The unnormalized data can be found in Table S3. The estimated $\mathrm{F}_{a e r}$ ( $\Delta$ FNET in Table S3) in the free-running simulation is about $-1.7 \mathrm{~W} \mathrm{~m}^{-2}$ (about $-2.4 \mathrm{~W} \mathrm{~m}^{-2}$ for the shortwave component and $-0.7 \mathrm{~W} \mathrm{~m}^{-2}$ for the longwave). This is consistent with the effective aerosol forcing estimate in EAMv1 reported in Golaz et al. (2019). Both of the wind-only nudged simulations (RNDG_UV and NDG_ERA5_UV) provide similar $\mathrm{F}_{\text {aer }}$ estimates (orange and yellow bars) as in CLIM (dark grey bars) and the differences between them are smaller than the ensemble spread in CLIM simulations.

When the temperature is nudged (in addition to horizontal winds), the model nudged towards CLIM (RNDG_UVT6, blue bars) provides a reasonable estimate for the longwave, but an underestimated $\mathrm{F}_{a e r}$ estimate for the shortwave (more than 20\% reduction). The impact of temperature nudging is much larger when EAM is nudged towards ERA5 reanalysis. Compared to the CLIM, NDG_ERA5_UVT (magenta bars) produces a more than $25 \%$ reduction for the shortwave ( $\Delta \mathrm{FSNT}$ ), and about a $50 \%$ reduction the longwave ( $\triangle \mathrm{FLNT}$ ). The change in the ice water path ( $\Delta$ IWP in Table S3) also decreases by more than a factor 2. Over the tropics (Figure 12c- $\mathrm{d}$ and Table S4), the impact is even larger, with about $40 \% \mathrm{~F}_{a e r}$ reduction in the shortwave, and about a 65\% reduction in the longwave. These results are consistent with those in Zhang et al. (2014) which showed that the temperature nudging in the CAM5 model leads to substantial decrease in the ice cloud amount and the impact of anthropogenic aerosols on longwave radiation is weaker. This suggests there still exist significant temperature biases in EAMv1 and the simulated ice formation is still sensitive to the anthropogenic aerosol concentrations.

Overall, our results indicate that nudging the horizontal winds but not temperature towards the ERA5 reanalysis or EAM's own meteorology is the preferred simulation configuration to estimate $\mathrm{F}_{\text {aer }}$. When only the winds are nudged, we expect changing the nudging tendency calculation location or using high-frequency nudging data won't have a significant impact on $\mathrm{F}_{a e r}$, since the impact on the present-day simulations are already very small.

\section{Conclusions}

Nudging has been widely used in the development and evaluation of global and regional atmospheric models. In this work, we further improved the nudging implementation in EAMv1 (Sun et al., 2019) and evaluated the impact on the climate representation, nudged hindcast skill, and the estimation of anthropogenic aerosol effect in the model. 

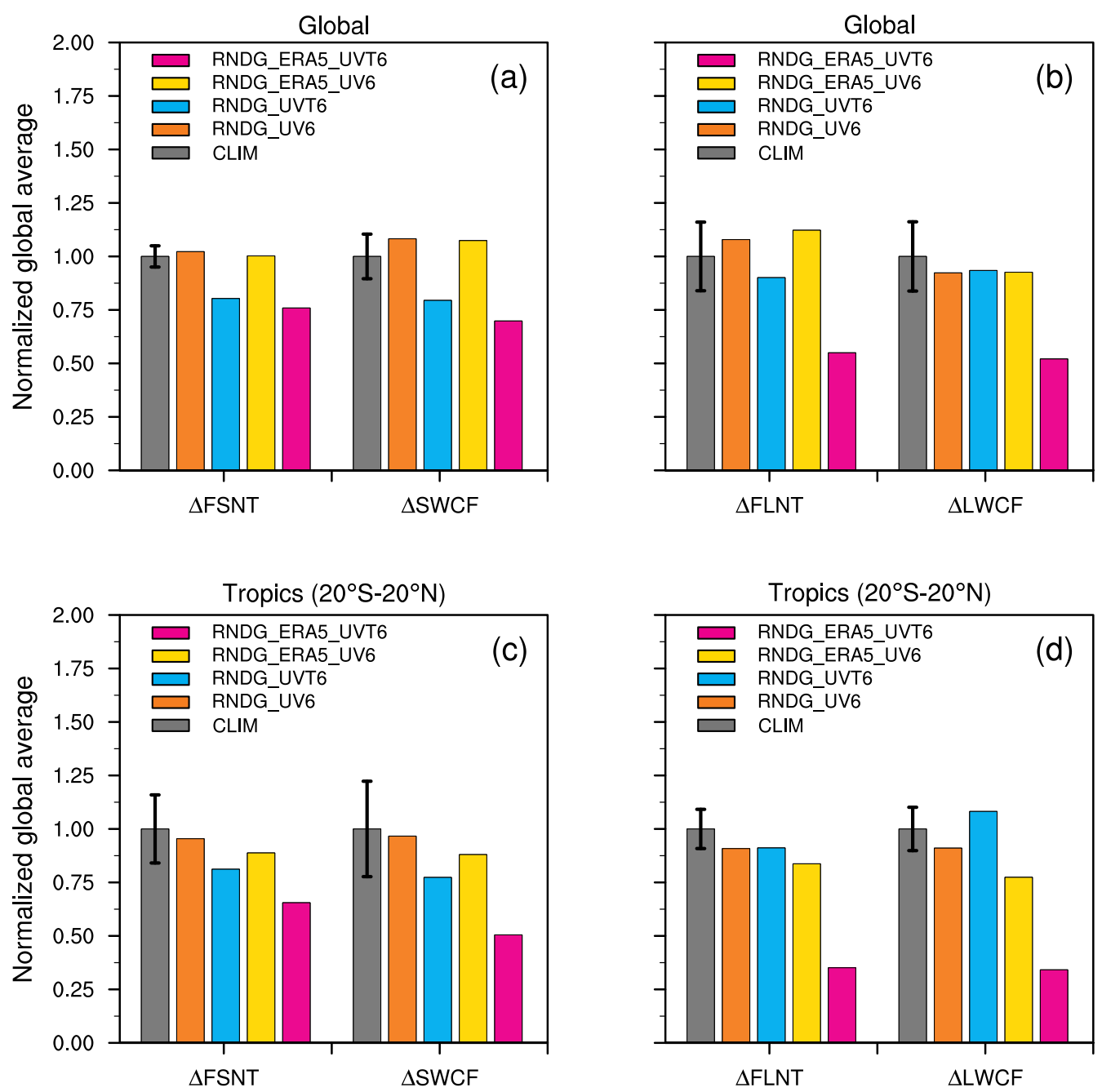

Figure 12. Normalized global (a-b) and topical (c-d) mean annually averaged anthropogenic aerosol effect (PD-PI differences, denoted by $\Delta$ ) in the free-running and nudged EAM simulations. FSNT/FLNT is the TOA net shortwave/longwave radiation flux and SWCF/LWCF the shortwave/longwave cloud radiative effects. The vertical thin line and whiskers associated to dark grey bar indicates the standard deviation of the 5-ensembles in CLIM. Results from nudged simulations are normalized by the corresponding ensemble average PD-PI differences from CLIM. The unnormalized data can be found in Table S3. The simulations are described in Section 2.3 and Table 1. 
https://doi.org/10.5194/gmd-2022-10

Preprint. Discussion started: 3 February 2022

(C) Author(s) 2022. CC BY 4.0 License.

The study was motivated by an unresolved issue in Sun et al. (2019), namely a nudged EAMv1 simulation constrained by EAMv1's own meteorology showed non-negligible local deviations from the baseline, with annually averaged SWCF changes on the order of 4-8 $\mathrm{W} \mathrm{m}^{-2}$ over some of the subtropical marine stratocumulus and trade cumulus regions. Two reasons were identified: First, EAMv1 outputs meteorological fields (from a baseline simulation) for nudging before the radiation parameterization, but the nudging tendency is calculated at a different place (after the dynamical core). This inconsistency introduced an extra term in the nudging tendency that was proportional to the effect of deep convection, shallow convection, and cloud microphysics on the simulated atmosphere (Section 3.1). Second, the EAM-simulated winds and temperature in the lower troposphere were found to have high-frequency modes with non-negligible magnitudes. For example, the zonal wind in the Peruvian stratocumulus region was found to have a prominent 12-hour cycle. Such variations cannot be properly captured by a 6-hourly sampling frequency, hence resulting in significant aliasing issues with the constraining data used for nudging (Section 3.2). We showed that by moving the calculation of nudging tendency to the same location as data output (Fig. 1b) and by increasing the frequency of constraining data to 3-hourly, one could largely remove the discrepancies between a freerunning EAMv1 simulation and a nudged simulation constrained by EAM's own meteorology. Further increasing the data frequency to hourly only provided marginal improvements. For future studies that nudge EAM towards its own meteorology, we recommend using the revised implementation and the 3-hourly constraining data. Table A1 shows an example on how to use the revised nudging implementation and change the constraining data frequency via namelist changes.

These improvements further motivated us to investigate the potential benefits of using the ERA5 reanalysis data, which are available at a higher frequency compared to ERA-Interim, for nudged hindcast simulations. In terms of the annual mean fields, there were discernible but small regional changes when switching from ERA-Interim to ERA5 or changing the constraining data frequency with ERA5. The impacts on global mean climate were found to be small (Section 4.1). Satellite retrievals for OLR and precipitation were used to evaluate the model hindcast skill in capturing real weather events. When ERA5 was used instead of ERA-Interim, the simulated OLR and precipitation are significantly improved, especially in the tropics. We also evaluated the model using radiosonde measurements from three ARM sites that have very different climate conditions. The simulated meteorological fields (winds, temperature, and relative humidity) were improved when replacing ERA-Interim with ERA5 and when higher-frequency nudging data are used. Significant improvements are seen in the mid and high-latitude ARM sites (SGP and NSA), but there are no tangible improvements at the tropical sites (TWPC1-3). At SGP and NSA, nudging winds and temperature together can further improve the model hindcast skill. The overall good agreements in the meteorological conditions between the nudged EAMv1 simulations and ARM observations provide a good basis for using ARM measurements to identify parameterizations deficiencies and improve the representation of cloud and aerosol related atmospheric processes.

Last but not least, we evaluated the impact of nudging implementation on the estimated anthropogenic aerosol indirect effects $\left(\mathrm{F}_{a e r}\right)$. Results show that when only winds in EAMv1 are nudged either towards a baseline simulation or ERA5 reanalysis, the estimated global mean $\mathrm{F}_{a e r}$ is very close to the estimates from free-running simulations. Consistent with Zhang et al. (2014), EAMv1 simulations nudged to temperature from the ERA5 reanalysis show significant changes in the $\mathrm{F}_{a e r}$ estimates when compared with the free-running baseline. In particular, the longwave $\mathrm{F}_{a e r}$ estimated from the EAMv1 simulations nudged 
https://doi.org/10.5194/gmd-2022-10

Preprint. Discussion started: 3 February 2022

(c) Author(s) 2022. CC BY 4.0 License.

(c) (1)

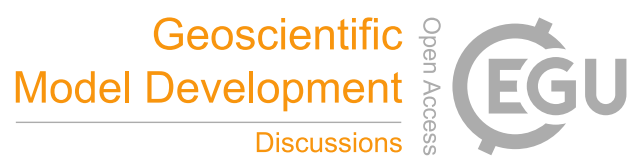

towards ERA5 reanalysis is a factor of 2 smaller compared to the free-running baseline. Therefore, for the $\mathrm{F}_{a e r}$ estimate, nudging the horizontal winds but not temperature is still the preferred simulation configuration for EAM.

410 We note that the 1-degree configuration of EAM was used in this study. The benefits of higher temporal and spatial resolutions of the ERA5 data might not have be fully revealed yet. As pointed by Jeuken et al. (1996), the linear temporal interpolation in nudging can become more questionable for higher-resolution simulations as more small time scale processes are resolved. Also, compared to ERA-Interim, the high-resolution ERA5 data can provide more accurate meteorological variables at model resolved scale, so the ERA5-nudged simulation might perform even better at high resolutions. The high-resolution configura-

415 tion of EAMv1 is substantially more expensive, so in this study we were not able to evaluate the nudging application at higher resolutions. However, with the upcoming release of EAMv2, the use of the new physics grid (Hannah et al., 2021) and semiLargragian advection scheme (Bradley et al., 2019) can substantially reduce the cost. Further work is needed to investigate whether there is additional benefit of using ERA5 in the global high-resolution simulations. 
https://doi.org/10.5194/gmd-2022-10

Preprint. Discussion started: 3 February 2022

(c) Author(s) 2022. CC BY 4.0 License.

(c) (i)

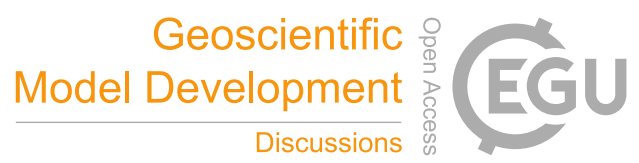

Appendix A: Supporting Information

A1 Nudging-related namelist setups for EAMv1 simulations

Table A1. List of the setups for nudging-related namelist variables in DNDG_ERAI_UVT6 and RNDG_ERA5_UVT3 conducted with EAMv1 in this study. The nudging-related setups in DNDG_ERAI_UVT6 followed the default EAMv1 with the sequence of calculation shown in Fig 1a. The RNDG_ERAI_UVT6 used the sequence of calculation shown in Fig $1 \mathrm{~b}$ with the revised nudging-related setups (rows in bold face) suggested by this study. See Table 1 and Section 2.3 in the main text for the detailed descriptions for DNDG_ERAI_UVT6 and RNDG_ERA5_UVT3.

\begin{tabular}{lll}
\hline \&nudging_nl & DNDG_ERAI_UVT6 & RNDG_ERA5_UVT3 \\
\hline nudge_model & .True. & .True. \\
nudge_method & 'Linear' & 'Linear' \\
nudge_currentstep & .False. & .False. \\
Nudge_loc_physout & .False. & .True. \\
nudge_tau & 6.0 & 6.0 \\
model_times_per_day & 48 & 48 \\
nudge_times_per_day & $\mathbf{4}$ & $\mathbf{8}$ \\
nudge_ucoef & 1.0 & 1.0 \\
nudge_uprof & 1 & 1 \\
nudge_vcoef & 1.0 & 1.0 \\
nudge_vprof & 1 & 1 \\
nudge_tcoef & 1.0 & 1.0 \\
nudge_tprof & 1 & 1 \\
nudge_qcoef & 0.0 & 0.0 \\
nudge_qprof & 0 & 0 \\
nudge_pscoef & 0.0 & './ERA-Interim/' \\
nudge_psprof & 'interim_se_\%y-\%m-\%d-\%s.nc' & 'era5_ne30L72_\%y-\%m-\%d-\%s.nc' \\
nudge_path & 1 & 1 \\
nudge_file_template & 2009 & 2009 \\
nudge_file_ntime & 10 & 10 \\
nudge_beg_year & 1 & 1 \\
nudge_beg_month & 2011 & 2011 \\
nudge_beg_day & 1 & 1 \\
nudge_end_year & 1 & 1 \\
nudge_end_month & & \\
nudge_end_day & & \\
\hline
\end{tabular}


https://doi.org/10.5194/gmd-2022-10

Preprint. Discussion started: 3 February 2022

(c) Author(s) 2022. CC BY 4.0 License.

(c) (i)

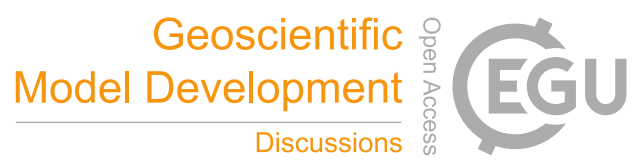

\section{A2 Method to generate error metrics for Figure 5}

The physical qualities listed in Table A2 are used to construct the error metics for the evaluation of nudged simulations in EAMv1. These physical quantities have also been widely used to evaluate climate model fidelity (e.g., Donahue and Caldwell, 2018; Wan et al., 2021). The error metrics as shown in Figure 5 include the relative differences in the simulated global averages and the relative differences in global patterns between the test simulations and the reference simulation conducted by EAM. Following Wan et al. (2021), the relative difference in simulated global averages are defined as the mean differences between the test simulation and reference simulation, normalized by the annual mean value from the reference simulation. While the relative difference in global pattern is defined as the centered root-mean-square (RMS) differences of the patterns between the test simulation and reference simulation, normalized by the RMS of the pattern in the reference simulation. A "pattern" here represents the annal mean, global, geographical distribution of a physical quantity.

Table A2. List of observational data and EAM's output used for evaluating the nudged simulations. The observational data were obtained from NCAR AMWG diagnostics package (http://www.cgd.ucar.edu/amp/amwg/diagnostics/plotType.html).

\begin{tabular}{ll}
\hline Physical quantity & EAM output \\
\hline Surface longwave downwelling flux & FLDS \\
Surface net longwave flux & FLNS \\
TOA upward longwave flux & FLUT \\
TOA clearsky upward longwave flux & FLUTC \\
Surface net shortwave flux & FSNS \\
TOA net shortwave flux & FSNTOA \\
TOA clearsky net shortwave flux & FSNTOAC \\
Longwave cloud forcing & LWCF \\
Shortwave cloud forcing & SWCF \\
Total cloud amount & CLDTOT \\
200 hPa zonal wind & U \\
500 hPa geopotential height & Z3 \\
Precipitation rate & PRECT \\
Total precipitable water & TMQ \\
Sea level pressure & PSL \\
Surface latent heat flux & LHFLX \\
Surface sensible heat flux & SHFLX \\
Surface stress & TAUX, TAUY \\
2m air temperature & TREFHT \\
Sea level temperature on land & TS \\
\hline
\end{tabular}


https://doi.org/10.5194/gmd-2022-10

Preprint. Discussion started: 3 February 2022

(c) Author(s) 2022. CC BY 4.0 License.

(c) (i)

\section{A3 Additional figures}
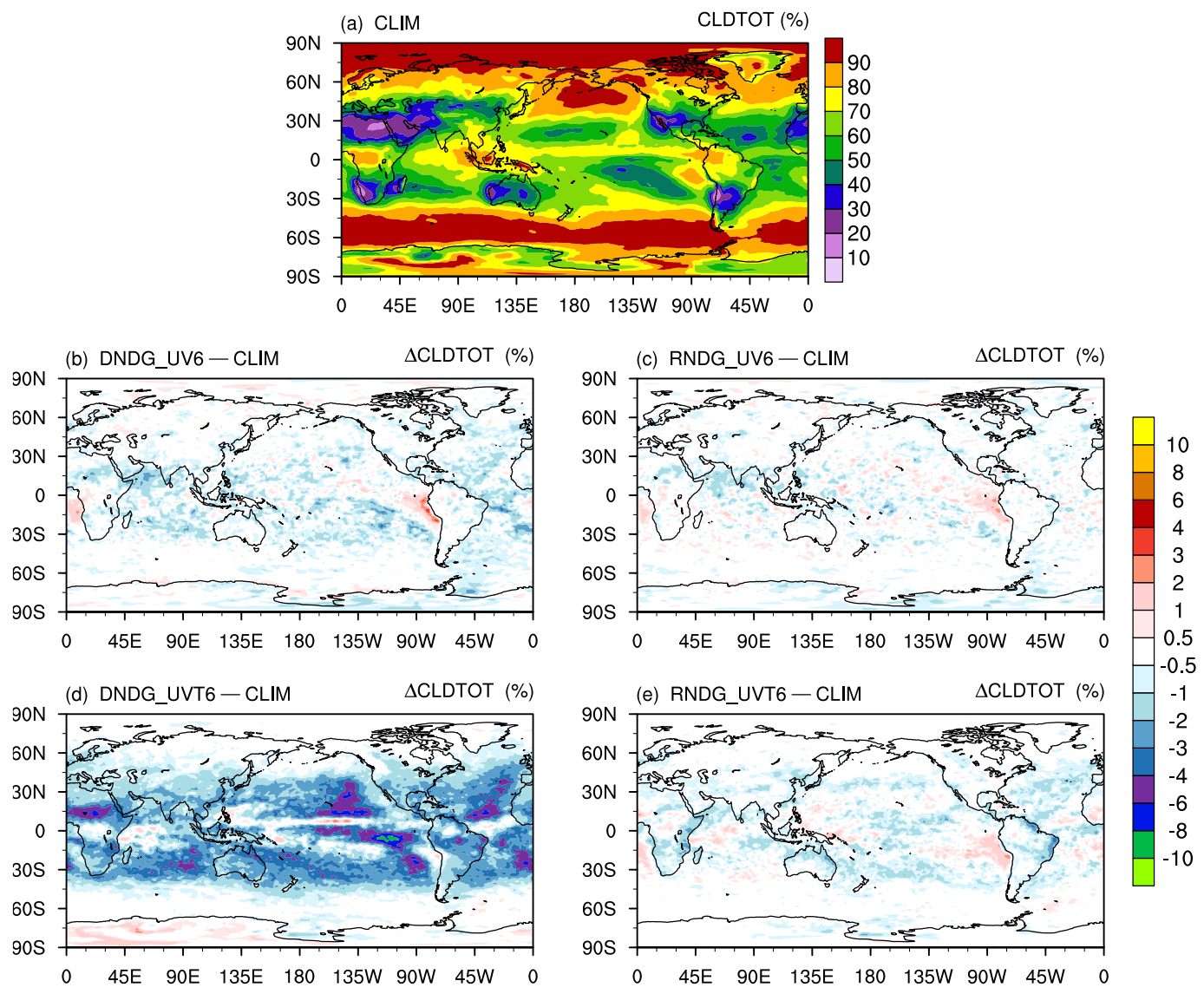

Figure A1. As in Figure 2 but showing results for the total cloud fraction fields (CLDTOT, unit: percent). The simulation setups are described in Section 2.3 and Table 1. 
https://doi.org/10.5194/gmd-2022-10

Preprint. Discussion started: 3 February 2022

(c) Author(s) 2022. CC BY 4.0 License.

\section{(c) (i)}

(a) CLIM

$\mathrm{CF}\left(\mathrm{W} \mathrm{m}^{-2}\right)$
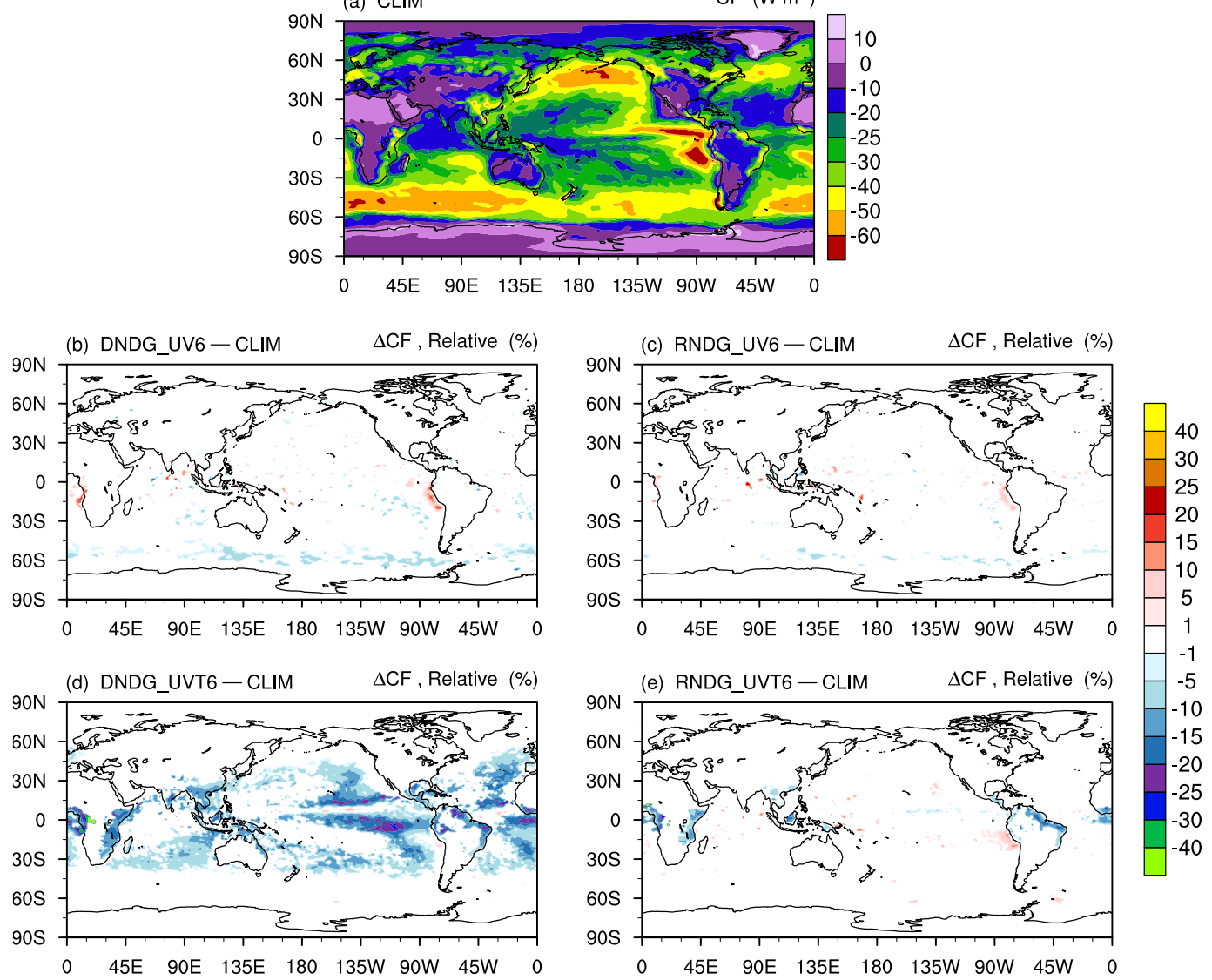

Figure A2. As in Fig. 2 but showing the relative differences in total cloud forcing (CF, unit: $\mathrm{W} \mathrm{m}^{-2}$ ) in panels (b)-(e). The simulation setups are described in Section 2.3 and Table 1.

(a) ERAI - ERA5

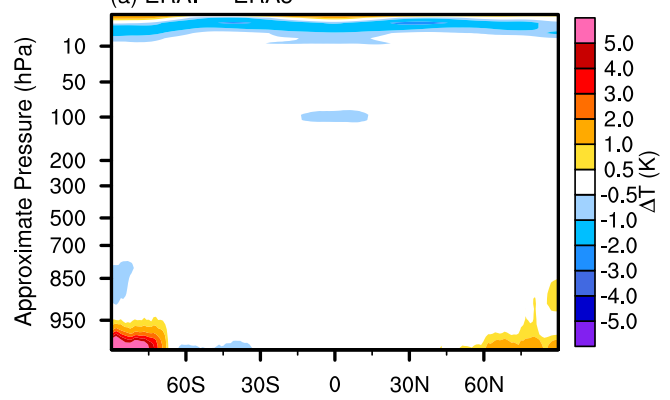

(b) CLIM - ERA5

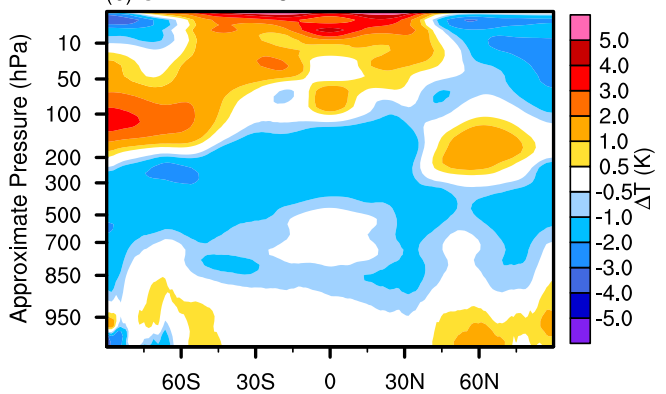

Figure A3. Year 2010 annual mean zonally averaged temperature differences ( $\Delta$ T, unit: K) between ERA-Interim ("ERAI") and ERA5 (panel a), and between EAMv1's free-running simulation CLIM and ERA5 (panel b). 
(a) $\operatorname{TRMM}\left(10^{\circ} \mathrm{S}-10^{\circ} \mathrm{N}\right)$

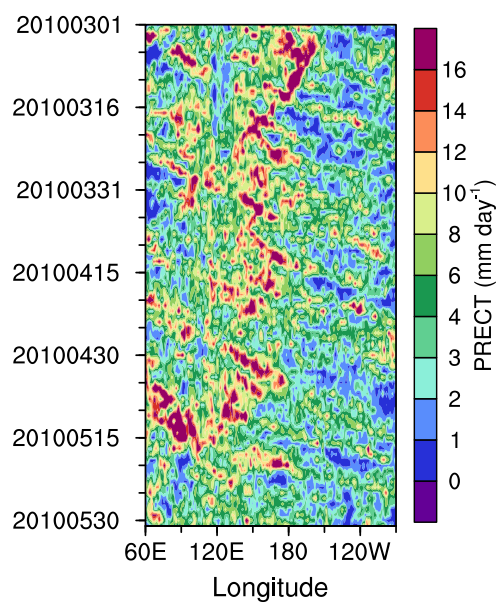

(d) TRMM $\left(25^{\circ} \mathrm{N}-50^{\circ} \mathrm{N}\right)$

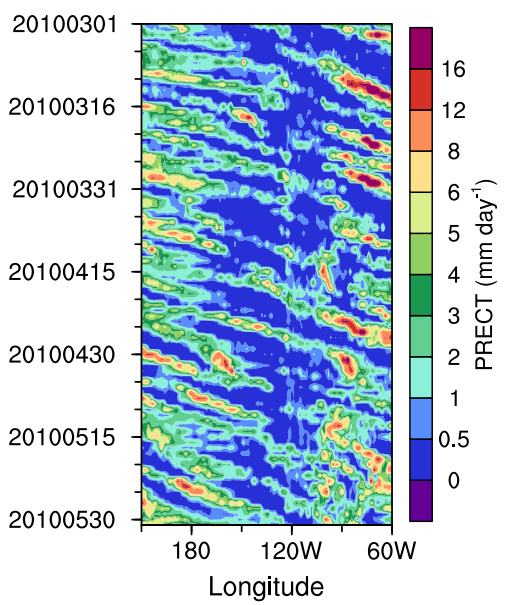

(b) Nudged to ERAI or ERA5

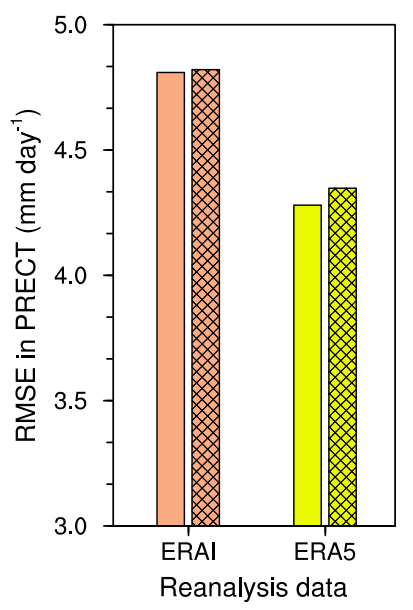

(e) Nudged to ERAI or ERA5

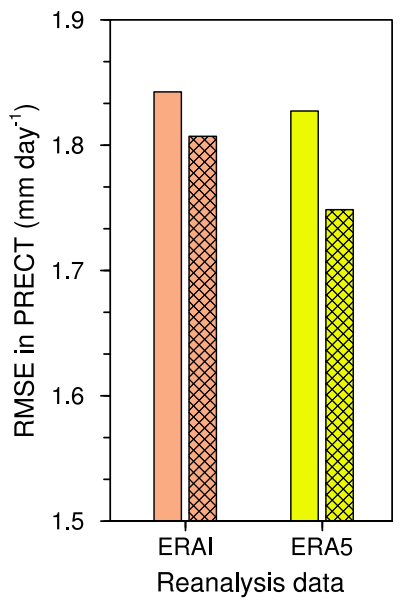

(c) Nudged to ERA5

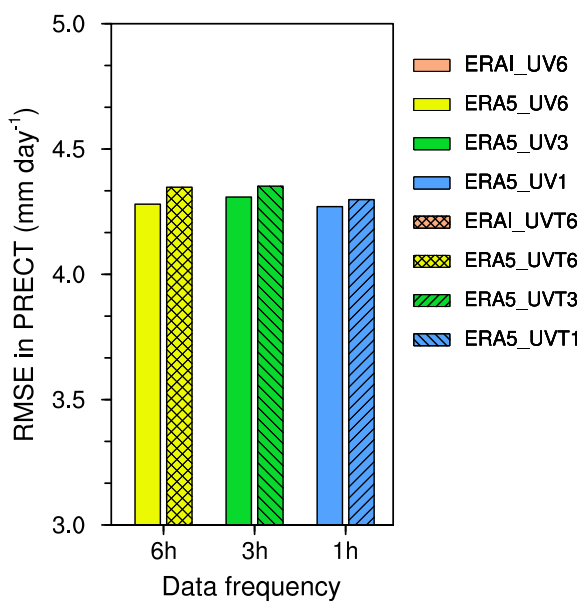

(f) Nudged to ERA5

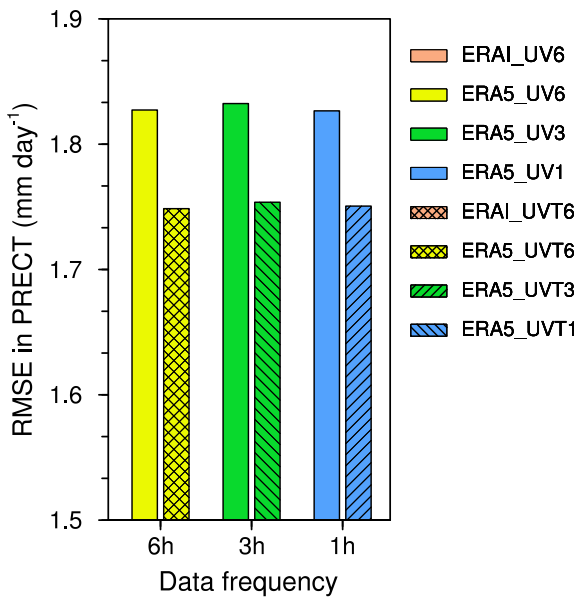

Figure A4. As in Figure 9 but the root-mean-square-errors (RMSEs) between a Hovmöller diagram derived from TRMM and the Hovmöller diagram derived from various nudged simulations are shown in panels $(b-c)$ and $(e-f)$. The simulation setups are described in Section 2.3 and Table 1 . 

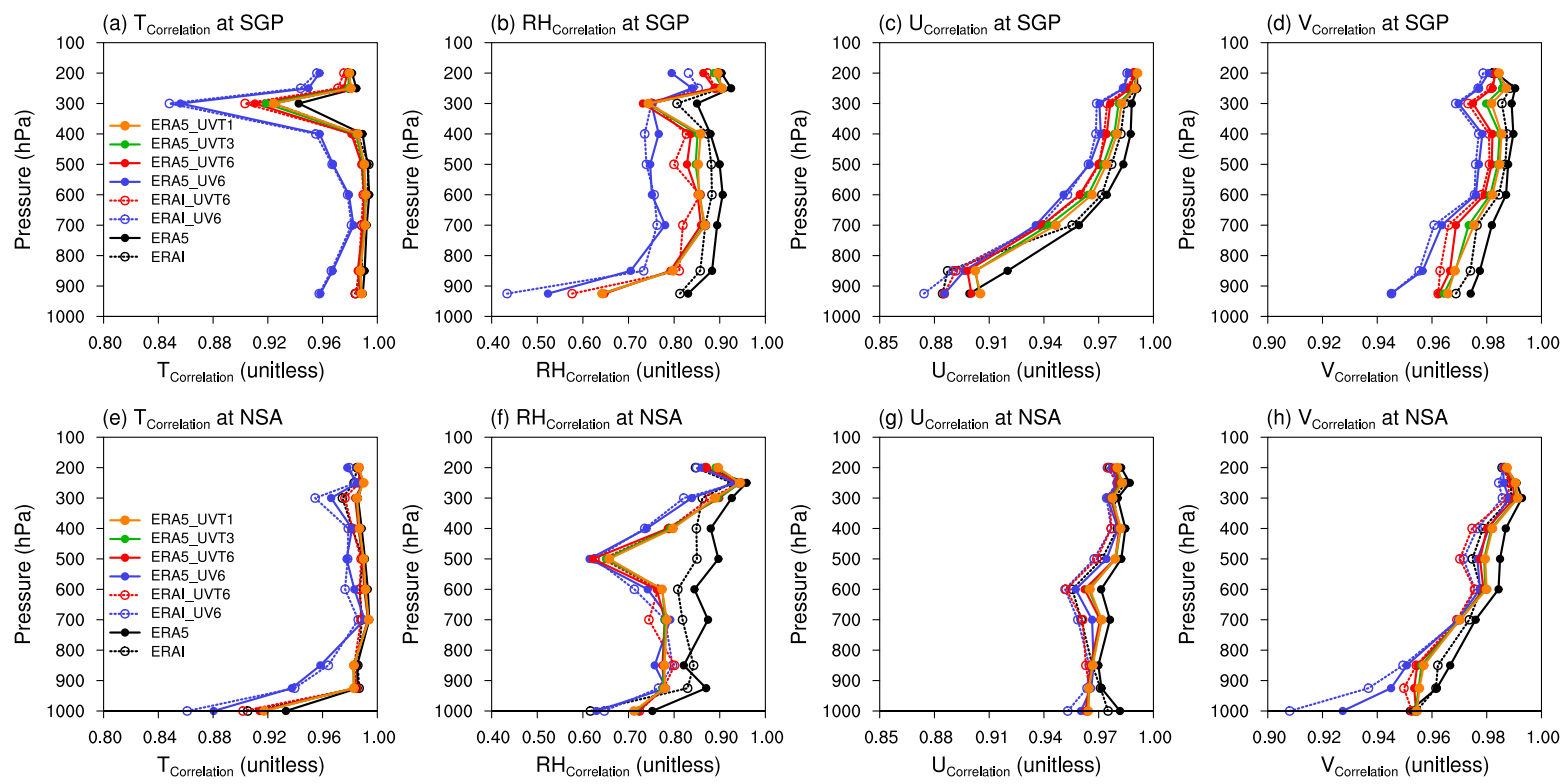

Figure A5. As in Fig. 10 but showing the temporal correlations between various nudged simulations (colored lines) or reanalysis products (ERA-Interim and ERA5, black lines) and the ARM measurements. The simulation setups are described in Section 2.3 and Table 1. 

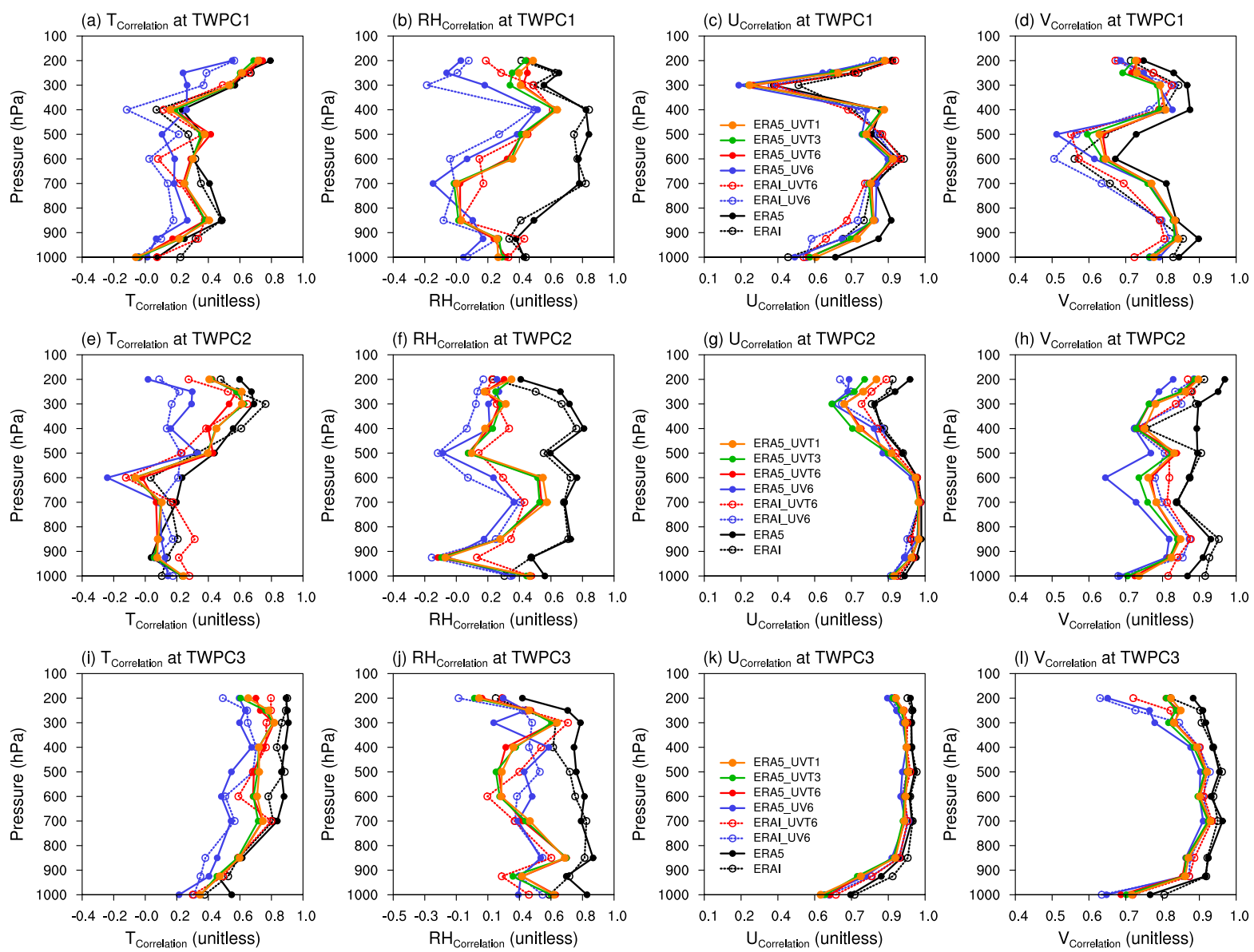

Figure A6. As in Fig. 11 but showing the temporal correlations between various nudged simulations (colored lines) or reanalysis products (ERA-Interim and ERA5, black lines) and the ARM measurements. The simulation setups are described in Section 2.3 and Table 1. 
https://doi.org/10.5194/gmd-2022-10

Preprint. Discussion started: 3 February 2022

(c) Author(s) 2022. CC BY 4.0 License.

(c) (1)

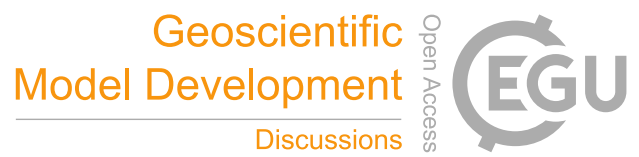

Code availability. The EAMv1 source code and run scripts used in this study can be found on Zenodo at https://doi.org/10.5281/zenodo. 5532606 (E3SM developers et al., 2021).

Data availability. The data for the analyses in this study can be found on Zenodo at https://doi.org/10.5281/zenodo.5839008 (Zhang and

Zhang, 2022). Radiosonde measurements at the SGP, NSA, TWPC1, TWPC2 and TWPC3 sites were obtained from the ARM user facility (http://dx.doi.org/10.5439/1021460), a DOE Office of Science user facility managed by BER. Satellite data used in this paper were obtained from the following sources

- https://pmm.nasa.gov/data-access/downloads/trmm for the TRMM 3B42 precipitation data,

- https://climatedataguide.ucar.edu/climate-data/persiann-cdr-precipitation-estimation-remotely-sensed-information-using-artificial for the PERSIANN-CDR precipitation data,

- https://climatedataguide.ucar.edu/climate-data/outgoing-longwave-radiation-olr-hirs for the HIRS OLR data,

- https://www.esrl.noaa.gov/psd/data/gridded/data.interp_OLR.html for the AVHRR OLR data.

Author contributions. KZ and HW initiated this study. HW identified the two nudging implementation issues. SZ conducted all simulations, processed the model output, and carried out the analyses with input from KZ and HW. SZ, KZ, and HW wrote the paper. All co-authors contributed to the revision.

Competing interests. The authors declare no competing interests

Acknowledgements. SZ and KZ were supported by the Laboratory Directed Research and Development Program at Pacific Northwest National Laboratory (PNNL), a multiprogram national laboratory operated by Battelle for the U.S. Department of Energy (DOE) under contract DE-AC05-76RL01830. KZ was also supported by DOE Office of Science, Office of Biological and Environmental Research (BER) via the Energy Exascale Earth System Model (E3SM) project. HW was supported by DOE BER via the Scientific Discovery through Advanced Computing (SciDAC) program (grant number: 70276). The EAMv1 code (DOI:10.11578/E3SM/dc.20180418.36) was obtained from the E3SM project sponsored by DOE BER. Computing resources were provided by DOE BER Earth System Modeling program's Compy computing cluster located at PNNL. 
https://doi.org/10.5194/gmd-2022-10

Preprint. Discussion started: 3 February 2022

(c) Author(s) 2022. CC BY 4.0 License.

(c) (i)

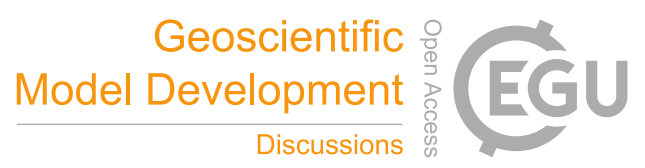

\section{References}

Ashouri, H., Hsu, K.-L., Sorooshian, S., Braithwaite, D. K., Knapp, K. R., Cecil, L. D., Nelson, B. R., and Prat, O. P.: PERSIANN-CDR: Daily precipitation climate data record from multisatellite observations for hydrological and climate studies, Bulletin of the American Meteorological Society, 96, 69-83, 2015.

Bradley, A. M., Bosler, P. A., Guba, O., Taylor, M. A., and Barnett, G. A.: Communication-Efficient Property Preservation in Tracer Transport, SIAM Journal on Scientific Computing, 41, C161-C193, https://doi.org/10.1137/18M1165414, 2019.

Dee, D. P., Uppala, S. M., Simmons, A. J., Berrisford, P., Poli, P., Kobayashi, S., Andrae, U., Balmaseda, M. A., Balsamo, G., Bauer, P., Bechtold, P., Beljaars, A. C. M., van de Berg, L., Bidlot, J., Bormann, N., Delsol, C., Dragani, R., Fuentes, M., Geer, A. J., Haimberger, L., Healy, S. B., Hersbach, H., Hólm, E. V., Isaksen, L., Kållberg, P., Köhler, M., Matricardi, M., McNally, A. P., Monge-Sanz, B. M., Morcrette, J.-J., Park, B.-K., Peubey, C., de Rosnay, P., Tavolato, C., Thépaut, J.-N., and Vitart, F.: The ERA-Interim reanalysis: configuration and performance of the data assimilation system, Quarterly Journal of the Royal Meteorological Society, 137, 553-597, https://doi.org/10.1002/qj.828, 2011.

Dennis, J. M., Edwards, J., Evans, K. J., Guba, O., Lauritzen, P. H., Mirin, A. A., St-Cyr, A., Taylor, M. A., and Worley, P. H.: CAM-SE: A scalable spectral element dynamical core for the Community Atmosphere Model,, Int. J. High Perform., 26, 74-89, https://doi.org/10.1177/1094342011428142, 2012.

Donahue, A. S. and Caldwell, P. M.: Impact of physics parameterization ordering in a global atmosphere model, Journal of Advances in Modeling Earth Systems, 10, 481-499, https://doi.org/10.1002/2017MS001067, 2018.

E3SM developers, Zhang, S., Zhang, K., and Sun, J.: EAM source code and scripts for nudging experiments in Zhang et. al. (2022, GMDD), https://doi.org/10.5281/zenodo.5532606, 2021.

Eyring, V., Bony, S., Meehl, G. A., Senior, C. A., Stevens, B., Stouffer, R. J., and Taylor, K. E.: Overview of the Coupled Model Intercomparison Project Phase 6 (CMIP6) experimental design and organization, Geoscientific Model Development, 9, 1937-1958, https://doi.org/10.5194/gmd-9-1937-2016, 2016.

Fast, J. D., Berg, L. K., Zhang, K., Easter, R. C., Ferrare, R. A., Hair, J. W., Hostetler, C. A., Liu, Y., Ortega, I., Sedlacek III, A., Shilling, J. E., Shrivastava, M., Springston, S. R., Tomlinson, J. M., Volkamer, R., Wilson, J., Zaveri, R. A., and Zelenyuk, A.: Model representations of aerosol layers transported from North America over the Atlantic Ocean during the Two-Column Aerosol Project, Journal of Geophysical Research: Atmospheres, 121, 9814-9848, https://doi.org/https://doi.org/10.1002/2016JD025248, 2016.

Feng, L., Smith, S. J., Braun, C., Crippa, M., Gidden, M. J., Hoesly, R., Klimont, Z., van Marle, M., van den Berg, M., and van der Werf, G. R.: The generation of gridded emissions data for CMIP6, Geoscientific Model Development, 13, 461-482, https://doi.org/10.5194/gmd13-461-2020, 2020.

Gates, W. L., Boyle, J. S., Covey, C., Dease, C. G., Doutriaux, C. M., Drach, R. S., Fiorino, M., Gleckler, P. J., Hnilo, J. J., Marlais, S. M., Phillips, T. J., Potter, G. L., Santer, B. D., Sperber, K. R., Taylor, K. E., and Williams, D. N.: An Overview of the Results of the Atmospheric Model Intercomparison Project (AMIP I), Bulletin of the American Meteorological Society, 80, 29-56, https://doi.org/10.1175/15200477(1999)080<0029:AOOTRO>2.0.CO;2, 1999.

Gelaro, R., McCarty, W., Suárez, M. J., Todling, R., Molod, A., Takacs, L., Randles, C. A., Darmenov, A., Bosilovich, M. G., Reichle, R., Wargan, K., Coy, L., Cullather, R., Draper, C., Akella, S., Buchard, V., Conaty, A., da Silva, A. M., Gu, W., Kim, G.-K., Koster, R., Lucchesi, R., Merkova, D., Nielsen, J. E., Partyka, G., Pawson, S., Putman, W., Rienecker, M., Schubert, S. D., Sienkiewicz, M., and 
https://doi.org/10.5194/gmd-2022-10

Preprint. Discussion started: 3 February 2022

(c) Author(s) 2022. CC BY 4.0 License.

(c) (i)

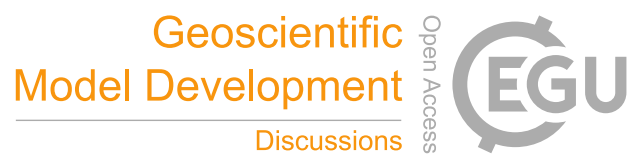

Zhao, B.: The Modern-Era Retrospective Analysis for Research and Applications, Version 2 (MERRA-2), Journal of Climate, 30,5419 5454, https://doi.org/10.1175/JCLI-D-16-0758.1, 2017.

Gettelman, A. and Morrison, H.: Advanced two-moment bulk microphysics for global models, Part I: Off-line tests and comparison with other schemes, Journal of Climate, 28, 1268-1287, https://doi.org/10.1175/JCLI-D-14-00102.1, 2015.

Ghan, S., Wang, M., Zhang, S., Ferrachat, S., Gettelman, A., Griesfeller, J., Kipling, Z., Lohmann, U., Morrison, H., Neubauer, D., Partridge, D. G., Stier, P., Takemura, T., Wang, H., and Zhang, K.: Challenges in constraining anthropogenic aerosol effects on cloud radiative forcing using present-day spatiotemporal variability, Proceedings of the National Academy of Sciences, 113, 5804-5811, https://doi.org/10.1073/pnas.1514036113, 2016.

Golaz, J.-C., Larson, V., and Cotton, W.: A PDF-Based Model for Boundary Layer Clouds. Part I: Method and Model Description, Journal of the Atmospheric Sciences, 59, 3540-3551, https://doi.org/10.1175/1520-0469(2002)059<3540:APBMFB>2.0.CO;2, 2002.

Golaz, J.-C., Caldwell, P. M., Van Roekel, L. P., Petersen, M. R., Tang, Q., Wolfe, J. D., Abeshu, G., Anantharaj, V., Asay-Davis, X. S., Bader, D. C., Baldwin, S. A., Bisht, G., Bogenschutz, P. A., Branstetter, M., Brunke, M. A., Brus, S. R., Burrows, S. M., Cameron-Smith, P. J., Donahue, A. S., Deakin, M., Easter, R. C., Evans, K. J., Feng, Y., Flanner, M., Foucar, J. G., Fyke, J. G., Griffin, B. M., Hannay, C., Harrop, B. E., Hoffman, M. J., Hunke, E. C., Jacob, R. L., Jacobsen, D. W., Jeffery, N., Jones, P. W., Keen, N. D., Klein, S. A., Larson, V. E., Leung, L. R., Li, H.-Y., Lin, W., Lipscomb, W. H., Ma, P.-L., Mahajan, S., Maltrud, M. E., Mametjanov, A., McClean, J. L., McCoy, R. B., Neale, R. B., Price, S. F., Qian, Y., Rasch, P. J., Reeves Eyre, J. E. J., Riley, W. J., Ringler, T. D., Roberts, A. F., Roesler, E. L., Salinger, A. G., Shaheen, Z., Shi, X., Singh, B., Tang, J., Taylor, M. A., Thornton, P. E., Turner, A. K., Veneziani, M., Wan, H., Wang, H., Wang, S., Williams, D. N., Wolfram, P. J., Worley, P. H., Xie, S., Yang, Y., Yoon, J.-H., Zelinka, M. D., Zender, C. S., Zeng, X., Zhang, C., Zhang, K., Zhang, Y., Zheng, X., Zhou, T., and Zhu, Q.: The DOE E3SM Coupled Model Version 1: Overview and Evaluation at Standard Resolution, Journal of Advances in Modeling Earth Systems, 11, 2089-2129, https://doi.org/https://doi.org/10.1029/2018MS001603, 2019.

Hannah, W. M., Bradley, A. M., Guba, O., Tang, Q., Golaz, J.-C., and Wolfe, J.: Separating Physics and Dynamics Grids for Improved Computational Efficiency in Spectral Element Earth System Models, Journal of Advances in Modeling Earth Systems, 13, e2020MS002 419, https://doi.org/https://doi.org/10.1029/2020MS002419, 2021.

Hersbach, H., Bell, B., Berrisford, P., Hirahara, S., Horányi, A., Muñz Sabater, J., Nicolas, J., Peubey, C., Radu, R., Schepers, D., Simmons, A., Soci, C., Abdalla, S., Abellan, X., Balsamo, G., Bechtold, P., Biavati, G., Bidlot, J., Bonavita, M., De Chiara, G., Dahlgren, P., Dee, D., Diamantakis, M., Dragani, R., Flemming, J., Forbes, R., Fuentes, M., Geer, A., Haimberger, L., Healy, S., Hogan, R. J., Hólm, E., Janisková, M., Keeley, S., Laloyaux, P., Lopez, P., Lupu, C., Radnoti, G., de Rosnay, P., Rozum, I., Vamborg, F., Villaume, S., and Thépaut, J.-N.: The ERA5 global reanalysis, Quarterly Journal of the Royal Meteorological Society, 146, 1999-2049, https://doi.org/https://doi.org/10.1002/qj.3803, 2020.

Hoesly, R. M., Smith, S. J., Feng, L., Klimont, Z., Janssens-Maenhout, G., Pitkanen, T., Seibert, J. J., Vu, L., Andres, R. J., Bolt, R. M., Bond, T. C., Dawidowski, L., Kholod, N., Kurokawa, J.-I., Li, M., Liu, L., Lu, Z., Moura, M. C. P., O’Rourke, P. R., and Zhang, Q.: Historical (1750-2014) anthropogenic emissions of reactive gases and aerosols from the Community Emissions Data System (CEDS), Geoscientific Model Development, 11, 369-408, https://doi.org/10.5194/gmd-11-369-2018, 2018.

Huffman, G. J. and Bolvin, D. T.: TRMM and other data precipitation data set documentation, NASA, Greenbelt, USA, $28,1,2013$.

Huffman, G. J., Bolvin, D. T., Nelkin, E. J., Wolff, D. B., Adler, R. F., Gu, G., Hong, Y., Bowman, K. P., and Stocker, E. F.: The TRMM multisatellite precipitation analysis (TMPA): Quasi-global, multiyear, combined-sensor precipitation estimates at fine scales, Journal of hydrometeorology, 8, 38-55, 2007. 
https://doi.org/10.5194/gmd-2022-10

Preprint. Discussion started: 3 February 2022

(C) Author(s) 2022. CC BY 4.0 License.

(c) (i)

Iacono, M. J., Delamere, J. S., Mlawer, E. J., Shephard, M. W., Clough, S. A., and Collins, W. D.: Radiative forcing by long-lived greenhouse gases: Calculations with the AER radiative transfer models, Journal of Geophysical Research: Atmospheres, 113 , D13 103, https://doi.org/10.1029/2008JD009944, 2008.

Jeuken, A. B. M., Siegmund, P. C., Heijboer, L. C., Feichter, J., and Bengtsson, L.: On the potential of assimilating meteorological analyses in a global climate model for the purpose of model validation, Journal of Geophysical Research: Atmospheres, 101, 16939-16950, https://doi.org/10.1029/96JD01218, 1996.

Kanamitsu, M., Ebisuzaki, W., Woollen, J., Yang, S.-K., Hnilo, J. J., Fiorino, M., and Potter, G. L.: NCEP-DOE AMIP-II Reanalysis (R-2), Bulletin of the American Meteorological Society, 83, 1631 - 1644, https://doi.org/10.1175/BAMS-83-11-1631, 2002.

535 Kooperman, G. J., Pritchard, M. S., Ghan, S. J., Wang, M., Somerville, R. C. J., and Russell, L. M.: Constraining the influence of natural variability to improve estimates of global aerosol indirect effects in a nudged version of the Community Atmosphere Model 5, Journal of Geophysical Research: Atmospheres, 117, https://doi.org/10.1029/2012JD018588, 2012.

Larson, V. E., Golaz, J.-C., and Cotton, W. R.: A PDF-Based Model for Boundary Layer Clouds. Part I: Method and Model Description, Journal of the Atmospheric Sciences, 59, 3519-3539, https://doi.org/10.1175/1520-0469(2002)059<3519:SSAMVI>2.0.CO;2, 2002.

Lee, H.-T., Gruber, A., Ellingson, R. G., and Laszlo, I.: Development of the HIRS Outgoing Longwave Radiation Climate Dataset, Journal of Atmospheric and Oceanic Technology, 24, 2029 - 2047, https://doi.org/10.1175/2007JTECHA989.1, 2007.

Lin, G., Wan, H., Zhang, K., Qian, Y., and Ghan, S. J.: Can nudging be used to quantify model sensitivities in precipitation and cloud forcing?, Journal of Advances in Modeling Earth Systems, 8, 1073-1091, https://doi.org/10.1002/2016MS000659, 2016.

Liu, X., Ma, P.-L., Wang, H., Tilmes, S., Singh, B., Easter, R. C., Ghan, S. J., and Rasch, P.: Description and evaluation of a new fourmode version of the Modal Aerosol Module (MAM4) within version 5.3 of the Community Atmosphere Model, Geoscientific Model Development, 9, 505-522, https://doi.org/doi.org/10.5194/gmd-9-505-2016, 2016.

Liu, Y., Zhang, K., Qian, Y., Wang, Y., Zou, Y., Song, Y., Wan, H., Liu, X., and Yang, X.-Q.: Investigation of short-term effective radiative forcing of fire aerosols over North America using nudged hindcast ensembles, Atmospheric Chemistry and Physics, 18, 31-47, https://doi.org/10.5194/acp-18-31-2018, 2018.

Lohmann, U. and Hoose, C.: Sensitivity studies of different aerosol indirect effects in mixed-phase clouds, Atmospheric Chemistry and Physics, 9, 8917-8934, https://doi.org/10.5194/acp-9-8917-2009, 2009.

Ma, H.-Y., Chuang, C. C., Klein, S. A., Lo, M.-H., Zhang, Y., Xie, S., Zheng, X., Ma, P.-L., Zhang, Y., and Phillips, T. J.: An improved hindcast approach for evaluation and diagnosis of physical processes in global climate models, Journal of Advances in Modeling Earth Systems, 7, 1810-1827, https://doi.org/10.1002/2015MS000490, 2015.

Ma, P.-L., Rasch, P. J., Fast, J. D., Easter, R. C., Gustafson Jr., W. I., Liu, X., Ghan, S. J., and Singh, B.: Assessing the CAM5 physics suite in the WRF-Chem model: implementation, resolution sensitivity, and a first evaluation for a regional case study, Geoscientific Model Development, 7, 755-778, https://doi.org/10.5194/gmd-7-755-2014, 2014.

Milrad, S.: Synoptic analysis and forecasting: An introductory toolkit, Elsevier, https://doi.org/https://doi.org/10.1016/C2015-0-05604-0, 2017.

560 Mlawer, E. J., Taubman, S. J., Brown, P. D., Iacono, M. J., and Clough, S. A.: Radiative transfer for inhomogeneous atmospheres: RRTM, a validated correlated?k model for the longwave, Journal of Geophysical Research: Atmospheres, 102, 16,663-16,682, https://doi.org/10.1029/97JD00237, 1997. 
https://doi.org/10.5194/gmd-2022-10

Preprint. Discussion started: 3 February 2022

(c) Author(s) 2022. CC BY 4.0 License.

(c) (i)

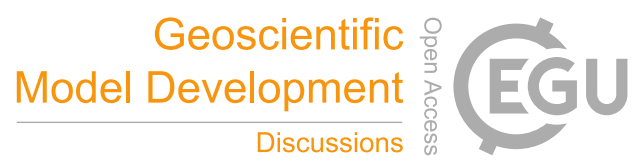

Morrison, H. and Gettelman, A.: A New Two-Moment Bulk Stratiform Cloud Microphysics Scheme in the Community Atmosphere Model,

Version 3 (CAM3). Part I: Description and Numerical Tests, Journal of Climate, 21, 3642-3659, https://doi.org/10.1175/2008JCLI2105.1, 2008.

Oleson, K., Lawrence, D., Gordon, B. B., Drewniak, B., Huang, M., Koven, C. D., Levis, S., Li, F., Riley, W. J., Subin, Z. M., Swenson, S. C., Thornton, P. E., Bozbiyik, A., Fisher, R., Heald, C. L., Kluzek, E., Lamarque, J., Lawrence, P. J., R., L. L., Sacks, W., Sun, Y., Tang, J., and Yang, Z.: Technical description of version 4.5 of the Community Land Model (CLM), Ncar technical note ncar/tn-503+str, NCAR, https://doi.org/10.5065/D6RR1W7M, 2013.

Rasch, P. J., Xie, S., Ma, P.-L., Lin, W., Wang, H., Tang, Q., Burrows, S. M., Caldwell, P., Zhang, K., Easter, R. C., Cameron-Smith, P., Singh, B., Wan, H., Golaz, J.-C., Harrop, B. E., Roesler, E., Bacmeister, J., Larson, V. E., Evans, K. J., Qian, Y., Taylor, M., Leung, L. R., Zhang, Y., Brent, L., Branstetter, M., Hannay, C., Mahajan, S., Mametjanov, A., Neale, R., Richter, J. H., Yoon, J.-H., Zender, C. S., Bader, D., Flanner, M., Foucar, J. G., Jacob, R., Keen, N., Klein, S. A., Liu, X., Salinger, A., Shrivastava, M., and Yang, Y.: An Overview of the Atmospheric Component of the Energy Exascale Earth System Model, Journal of Advances in Modeling Earth Systems, 11, 2377-2411, https://doi.org/10.1029/2019MS001629, 2019.

Reynolds, R. W., Rayner, N. A., Smith, T. M., Stokes, D. C., and Wang, W.: An Improved In Situ and Satellite SST Analysis for Climate, Journal of Climate, 15, 1609-1625, https://doi.org/10.1175/1520-0442(2002)015<1609:AIISAS>2.0.CO;2, 2002.

Separovic, L., de Elía, R., and Laprise, R.: Impact of spectral nudging and domain size in studies of RCM response to parameter modification, Climate dynamics, 38, 1325-1343, https://doi.org/10.1007/s00382-011-1072-7, 2012.

Stowe, L. L., Jacobowitz, H., Ohring, G., Knapp, K. R., and Nalli, N. R.: The Advanced Very High Resolution Radiometer (AVHRR) Pathfinder Atmosphere (PATMOS) Climate Dataset: Initial Analyses and Evaluations, Journal of Climate, 15, 1243 - 1260, https://doi.org/10.1175/1520-0442(2002)015<1243:TAVHRR>2.0.CO;2, 2002.

Subramanian, A. C. and Zhang, G. J.: Diagnosing MJO hindcast biases in NCAR CAM3 using nudging during the DYNAMO field campaign, Journal of Geophysical Research: Atmospheres, 119, 7231-7253, https://doi.org/10.1002/2013JD021370, 2014.

Sun, J., Zhang, K., Wan, H., Ma, P.-L., Tang, Q., and Zhang, S.: Impact of Nudging Strategy on the Climate Representativeness and Hindcast Skill of Constrained EAMv1 Simulations, Journal of Advances in Modeling Earth Systems, 11, 3911-3933, https://doi.org/10.1029/2019MS001831, 2019.

Taylor, M. A., Cyr, A. S., and Fournier, A.: A Non-oscillatory Advection Operator for the Compatible Spectral Element Method,, International Conference on Computational Science, Springer, Berlin, Heidelberg, https://doi.org/10.1007/978-3-642-01973-9_31, 2010.

Telford, P. J., Braesicke, P., Morgenstern, O., and Pyle, J. A.: Technical Note: Description and assessment of a nudged version of the new dynamics Unified Model, Atmospheric Chemistry and Physics, 8, 1701-1712, https://doi.org/10.5194/acp-8-1701-2008, 2008.

Wan, H., Rasch, P. J., Zhang, K., Qian, Y., Yan, H., and Zhao, C.: Short ensembles: an efficient method for discerning climate-relevant sensitivities in atmospheric general circulation models, Geoscientific Model Development, 7, 1961-1977, https://doi.org/10.5194/gmd-71961-2014, 2014.

595 Wan, H., Zhang, S., Rasch, P. J., Larson, V. E., Zeng, X., and Yan, H.: Quantifying and attributing time step sensitivities in present-day climate simulations conducted with EAMv1, Geoscientific Model Development, 14, 1921-1948, https://doi.org/10.5194/gmd-14-19212021, 2021.

Wang, H., Easter, R. C., Zhang, R., Ma, P.-L., Singh, B., Zhang, K., Ganguly, D., Rasch, P. J., Burrows, S. M., Ghan, S. J., Lou, S., Qian, Y., Yang, Y., Feng, Y., Flanner, M., Leung, L. R., Liu, X., Shrivastava, M., Sun, J., Tang, Q., Xie, S., and Yoon, J.-H.: Aerosols in the 
https://doi.org/10.5194/gmd-2022-10

Preprint. Discussion started: 3 February 2022

(c) Author(s) 2022. CC BY 4.0 License.

(c) (i)

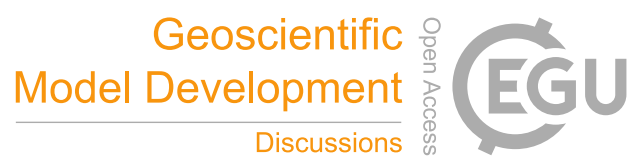

E3SM Version 1: New Developments and Their Impacts on Radiative Forcing, Journal of Advances in Modeling Earth Systems, 12, e2019MS001 851, https://doi.org/https://doi.org/10.1029/2019MS001851, 2020.

Wang, Y., Liu, X., Hoose, C., and Wang, B.: Different contact angledistributions for heterogeneous ice nucleation in the CommunityAtmospheric Model version 5, Atmospheric Chemistry and Physics, 14, 10411-10430, https://doi.org/doi.org/10.5194/acp-14-10411-2014, 2014.

Xie, S., Lin, W., Rasch, P. J., Ma, P.-L., Neale, R., Larson, V. E., Qian, Y., Bogenschutz, P. A., Caldwell, P., Cameron-Smith, P., Golaz, J.-C., Mahajan, S., Singh, B., Tang, Q., Wang, H., Yoon, J.-H., Zhang, K., and Zhang, Y.: Understanding Cloud and Convective Characteristics in Version 1 of the E3SM Atmosphere Model, Journal of Advances in Modeling Earth Systems, 10, 2618-2644, https://doi.org/https://doi.org/10.1029/2018MS001350, 2018.

Zhang, G. J. and McFarlane, N. A.: Sensitivity of climate simulations to the parameterization of cumulus convection in the Canadian Climate Centre general circulation model, Atmos. Ocean, 33, 407-446, https://doi.org/10.1080/07055900.1995.9649539, 1995.

Zhang, K., O’Donnell, D., Kazil, J., Stier, P., Kinne, S., Lohmann, U., Ferrachat, S., Croft, B., Quaas, J., Wan, H., Rast, S., and Feichter, J.: The global aerosol-climate model ECHAM-HAM, version 2: sensitivity to improvements in process representations, Atmospheric Chemistry and Physics, 12, 8911-8949, https://doi.org/10.5194/acp-12-8911-2012, 2012.

Zhang, K., Wan, H., Liu, X., Ghan, S. J., Kooperman, G. J., Ma, P.-L., Rasch, P. J., Neubauer, D., and Lohmann, U.: Technical Note: On the use of nudging for aerosol-climate model intercomparison studies, Atmospheric Chemistry and Physics, 14, 8631-8645, https://doi.org/10.5194/acp-14-8631-2014, 2014.

Zhang, K., Rasch, P. J., Taylor, M. A., Wan, H., Leung, R., Ma, P.-L., Golaz, J.-C., Wolfe, J., Lin, W., Singh, B., Burrows, S., Yoon, J.-H., Wang, H., Qian, Y., Tang, Q., Caldwell, P., and Xie, S.: Impact of numerical choices on water conservation in the E3SM Atmosphere Model version 1 (EAMv1), Geoscientific Model Development, 11, 1971-1988, https://doi.org/10.5194/gmd-11-1971-2018, 2018.

Zhang, K., Zhang, W., Wan, H., Rasch, P. J., Ghan, S. J., Easter, R. C., Shi, X., Wang, Y., Wang, H., Ma, P.-L., Zhang, S., Sun, J., Burrows, S., Shrivastava, M., Singh, B., Qian, Y., Liu, X., Golaz, J.-C., Tang, Q., Zheng, X., Xie, S., Lin, W., Feng, Y., Wang, M., Yoon, J.H., and Leung, R. L.: Effective radiative forcing of anthropogenic aerosols in E3SMv1: historical changes, causality, decomposition, and parameterization sensitivities, Atmospheric Chemistry and Physics Discussions, 2022, 1-49, https://doi.org/10.5194/acp-2021-1087, 2022.

Zhang, S. and Zhang, K.: Data for the analyses in Zhang et. al. (2022, GMDD), https://doi.org/10.5281/zenodo.5839008, 2022.

Zhang, S., Wang, M., Ghan, S. J., Ding, A., Wang, H., Zhang, K., Neubauer, D., Lohmann, U., Ferrachat, S., Takeamura, T., Gettelman, A., Morrison, H., Lee, Y., Shindell, D. T., Partridge, D. G., Stier, P., Kipling, Z., and Fu, C.: On the characteristics of aerosol indirect effect based on dynamic regimes in global climate models, Atmospheric Chemistry and Physics, 16, 2765-2783, https://doi.org/10.5194/acp16-2765-2016, 2016. 